\title{
دراسة تحليلية مقارنة لتقييم اداء صناعة المنتجات الغذائية في مصر
}

\author{
رحاب سعيد ابراهيم احمد \\ قسم الاقتصاد الزراعي، كلية الزراعة، جامعة عبن شمس
}

Received: Oct. 1, 2017

Accepted: Oct. 31,2017

الملخص

استهفف البحث دراسة تحلبلية مالية مقارنة لقطاع صناعة المنتجات الغذائية وللتعرف على أسباب ظهور الطاقات

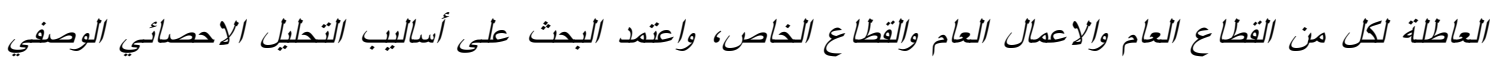

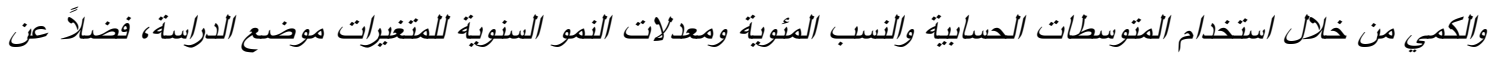

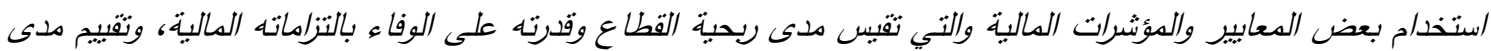

كفاءة القطاع الإنتاجية والتسويقية والإدراية.

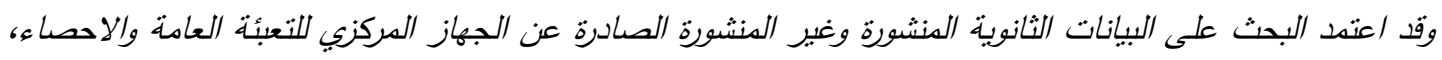

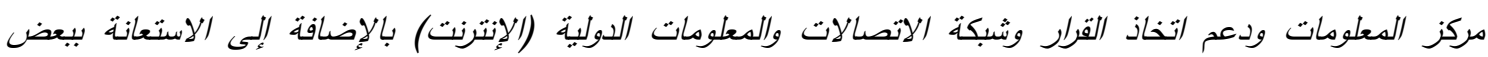
الدراسات والبحوث ذات الصلة بدوضوع ومنهجية البحث. وأوضحت ونتائج البحث:

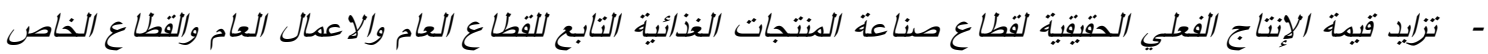
بدعدل ندو بلغ نحو 4.5\%، 5.5\% على الترتيب خلال الفترة (2007/2006-2014/2013)، كنلك تنزايدت قيمة

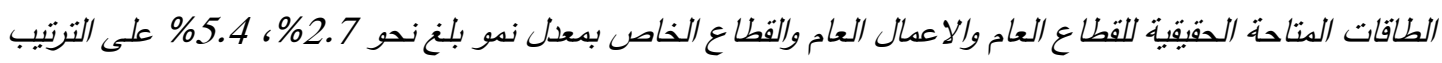
خلا نفس الفترة سالفة الذكر. - تأتي صعوبات التسويق كأحد الأسباب المرتبطة بظروف السوق في المتبة الأولى كأحد مسببات الطاقات العاطلة في

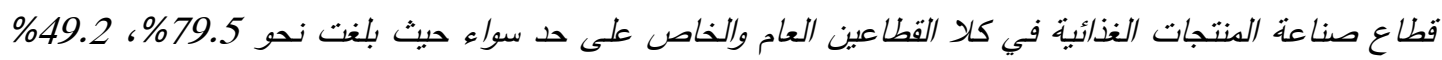
على التوالي خلال عام (2014/2013). ويأتي نقص الدواد الخام كأحد الأسباب الفنبة لظهور الطاقات العاطلة في المرتبة الثانية بنسبة 0.6\%، 13.4\% لكل من القطاع العام والقطاع الخاص على التوالي خلال عام (2014/2013).

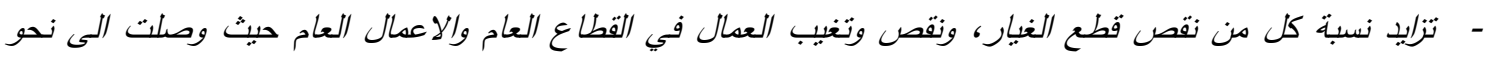

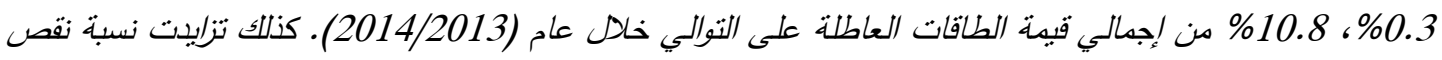
وتغيب العمال لتصل الى نحو 4.8 \%، في حين تناقصت نسبة نقص قطع الغيار كأحد اسباب ظهور الطاقات العاطلة في القطاع الخاص لتصل الى نحو 3.2\% في عام (2014/2013)، وقد برجع ذلك لتغير الظروف السياسية والاقتصادية في مصر خلال عام (2014/2013) الامر الذي ادى الى غياب الأبيدي العاملة الداهرة في كلا القطاعين

$$
\text { العام والخاص على حد سواء. }
$$

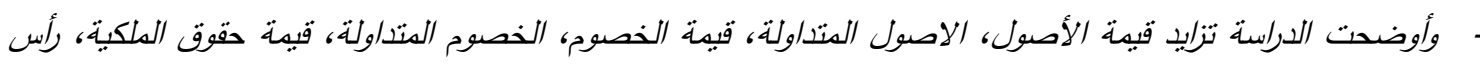

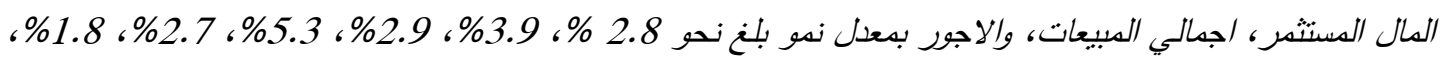

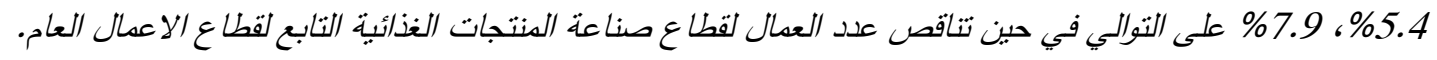

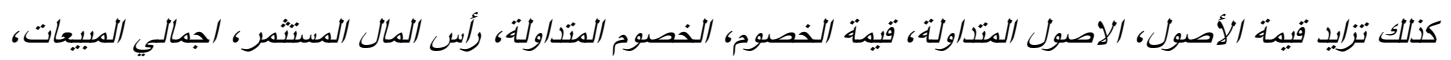

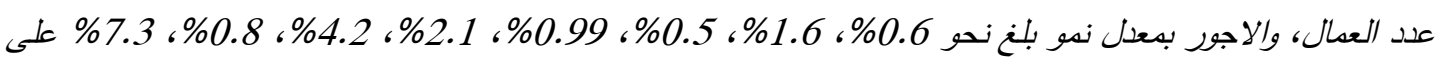

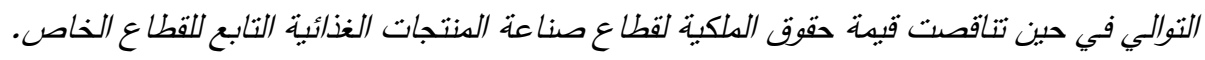


- ومن دراسة المؤشرات الدالية اتضح زيادة قدرة قطاع صناعة الدنتجات الغذائية بالقطاع الخاص على تحقيق أرباح من

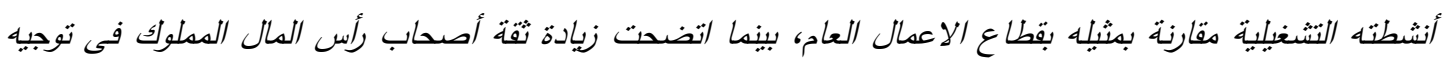

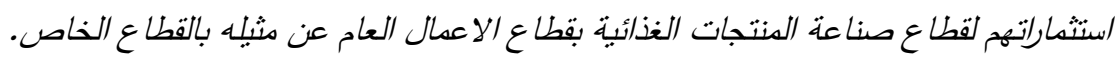

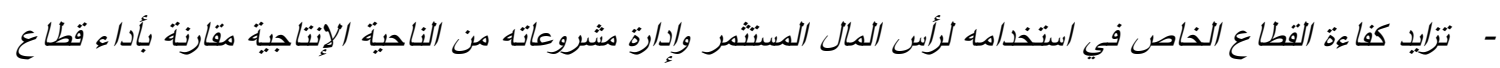
الاعمال العام خال فترة الدراسة.

- تزليد الصعويات التسويقية التي تواجه كلا القطاعين الا انها أكثر حدة بقطاع صناعة المنتجات الغذائية بقطاع الاعمال

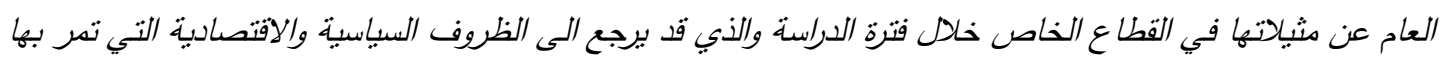
البلاد خلد تلك الفترة.

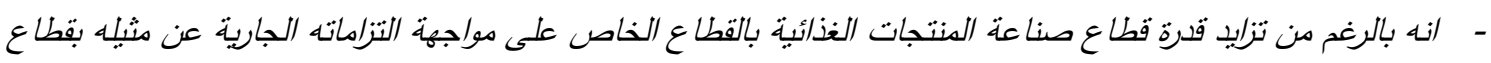
الاعمال العام الا ان كلا القطاعين غير قادر على مواجهة التزاماته في الظروف الطارئة والدلحة.

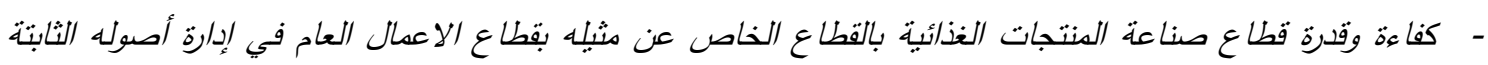
والدتداولة وزيادة استغلالمها وقدرتها على توليد المبيعات.

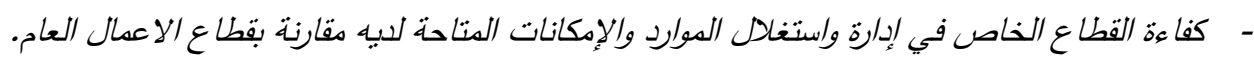

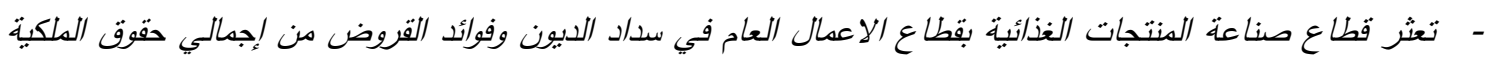

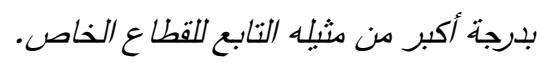
ويناءًا على ما سبق يوصى البحث بها لئي: 1- تثجيع استثارات القطاع الخاص في مجال صناعة المنتجات الغذائية جنباً الى جنب مع استثمارات قطاع الاعمال العام. 2- زيادة الانفاق الحكومي على البحث والتطوير كأحد أهم الثروط اللازمة لتطوير الفنون الانتاجية في قطاع صناعة المنتجات الغذائية وابتكار منتجات جبيدة تلاقى استحساناً لدى الافراد.

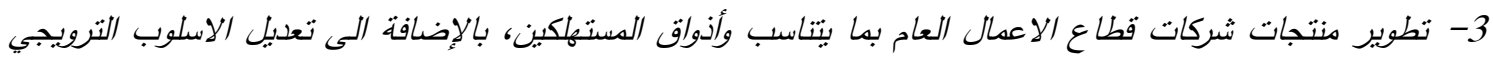

لكنتجاتهم بما يتناسب وظروف المجتمع الدصري.

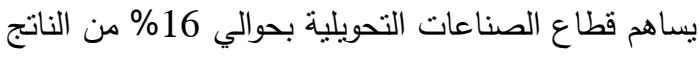

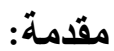
المحلى الإجمالي خلال عام (2013/2012) (جدول رقم

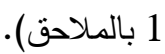

وتعتبر صناعة المنتجات الغذائبة من أهم الصناعات التحويلية التي تعتمد بصفة رئيسية على المنتجات الغذائية

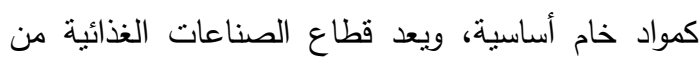
القطاعات الرائدة في الاقتصاد القومي المصري إنداد إذ يمنل

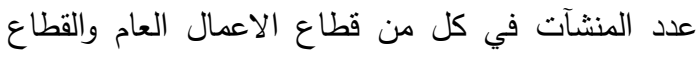
الخاص نحو 55\%11\% من إجمالي عدد المنشآت التابعة للصناعات التحويلية في كلا القطاعين على النوالي

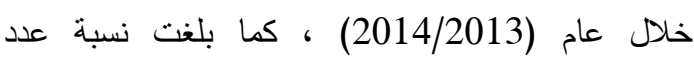
المشتغلين في قطاع المنتجات الغذائية في كل من قطاع لغاع 
والاعمال العام والقطاع الخاص خلال الفترة

.2014/2013-2007/2006)

3- تطور أهم معالم قطاع المنتجات الغذائية بكل من قطاع الاعمال العام والقطاع الخاص خلاع لفات الفترة

$$
\text { .2014/2013-2007/2006) }
$$

4- المؤشرات المالية لتقييم أداء قطاع المنتجات الغذائية

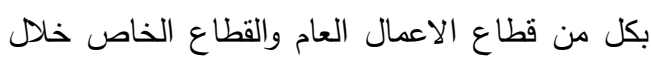
الفترة (2007/2006-2014/2013).

\section{الطريقة البحثية:}

قد اعتمد البحث على أساليب التحليل الاحصائي الوصفي والكمي من خلال استخدام المنوسطات الحسابية

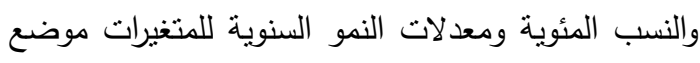
الدراسة، فضلاً عن استخدام بعض المعايير والمؤشرات المالية والتي تقبس مدى ربحية القطاع وقدرته على الوفاء بالتزاماته المالية، وتقييم مدى كفاءة القطاع الإنتاجية والتسويقية والإدارية.

$$
\text { 1-متئثتل هذه المعايير فيما يلي: }
$$

والتي تقيس قدرة المشروع على نوليد الأرباح من التمن أنشتطه التشغيلية، وتشتنل على المؤشرات التالية: أ- صافي العائد الى الإيرادات = (صافي الريح أو

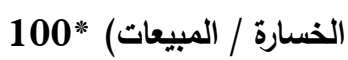

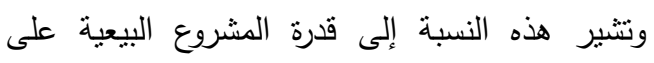

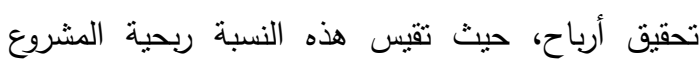

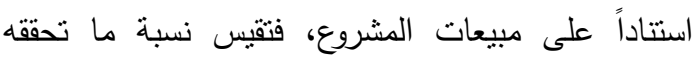

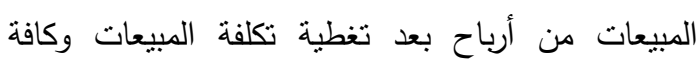

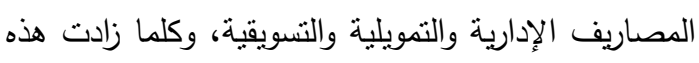

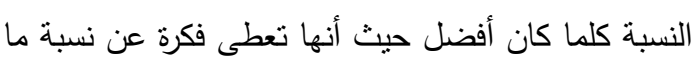
يتبقى من المبيعات كصافي ربح قابل للتوزيع.

ب- صافي العائد الى الأصول= (صافي الربح أو 100* الخسارة /لأصول)

وتتشير هذه النسبة إلى قدرة المشروع على إدارة أصوله
الاعمال العام والقطاع الخاص حوالى124\%8\%من جملة عدد المشتخلين في قطاع الصناعات التحويلية لكلا القطاعين على التوالي، كذلك بلغت نسبة قيمة الاصول

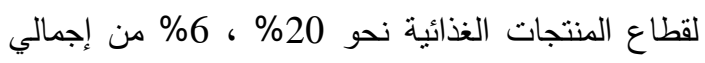

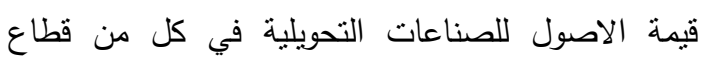

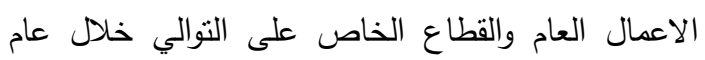
.(2014/2013)

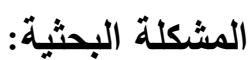

يواجه قطاع صناعة المنتجات الغذائية العديد من

التحديات بالرغم من أنه يعد من القطاعات الحيوية في

الاقتصاد القومي المصري حيث تمتل الطاقات العاطلة في لهي

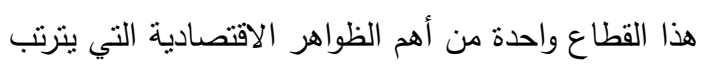

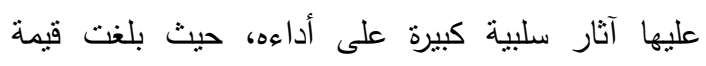
الطاقات العاطلة في قطاع صناعة المنتجات الغذائية

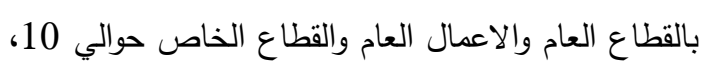
39 مليون جنيه تمثل نحو 10\% ، 12\% من إجمالي

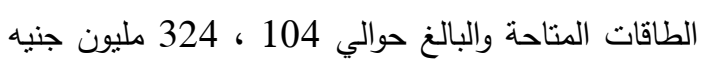
على النوالي خلال عام (2014/2013) في حين بلغت قيمة الانتاج الفعلي لكلا القطاعين حوالى 94 ، 285 مليون جنيه على التوالي خلال نفس العام.

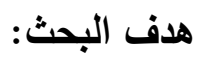

مما سبق بتضح أن البحث يستهدف دراسة تحليلية

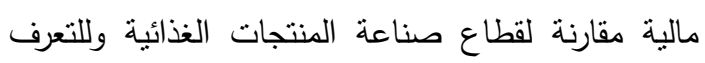
على أسباب ظهور الطاقات العاطلة لكل من القطاع العام والاعمال العام والقطاع الخاص.

ولتحقيق هذا الهدف سيتم دراسة الجوانب التالية: 1- تطور قيمة الإنتاج الفعلي والطاقات العاطلة والمتاحة

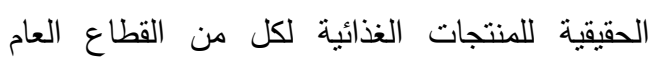

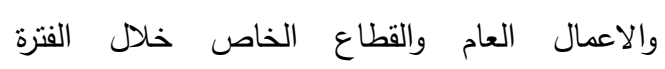
.2014/2013-2007/2006) 2- التوزيع النسبي لأسباب ظهور الطاقات العاطلة

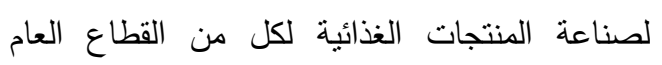


المستحقة)، لذلك فإنها تهدف لقياس قدرة المشروع على الكى مواجهة التزاماته في الاجل القصير (أي تقيم المركز الأاتتماني للمنشأة).

أ- نسبة التداول = الأصول المتداولة / الخصوم

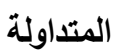

وتبين هذه النسبة مدى قدرة المنشأة في تسديد التزاماته

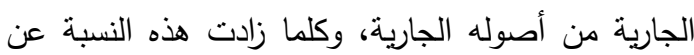
الواحد الصحيح دل على قدرة المشروع على الوفاء بالتزاماته والعكس صحيح.

ب- نسبة السيولة السريعة =الأرصدة النقاية/ الخصوم

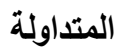

وهذه النسبة أثز تحفظاً من النسبة السابقة إذ تعتد على الأموال السائلة فعلاً حيث تأخذ في اعنبارها قيمة لكنة التشهيلات الايتمانية غير المستعملة والتي يمكن استخذامها لتغطية بعض أو كل عجز السيولة لمقابلة

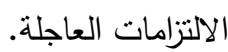

فإذا انخفضت هذه النسبة عن الواحد الصحيح دل

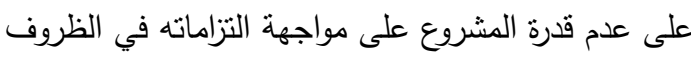
الطارئة والملحة، مما يجعله يلجأ الى نسييل بضاعنه بسعر قد يكون أحياناً أقل من التكلفة لتسديد النزاماته.

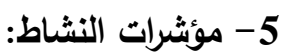

وهي دجموعة نسب تقبس مدى نجاح الثركة في إدارة وتتشيل أصولها (الموارد المتاحة) وتوليد المبيعات

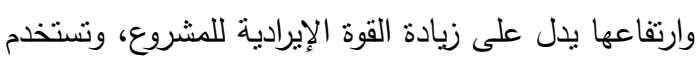
عادة لتقييم أداء المركز المالي للمنشأة.

أ- معدل دولان إجمالي الأصول= المبيعات / إجمالي الاصول ويثير الى كفاءة وقدرة الشروع على استخدام أصوله

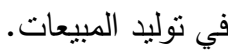
ب- معدل دولن الأصول المتداولة = المبيعات/ الأصول

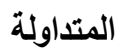

ويثير إلى كفاءة المنشأة في إدارة أصولها المتداولة وزيادة استغلالها وقدرتها على توليد المبيعات.
المختلفة، وتقيس هذه النسبة مدى ربحية المنشأة ككل، حيث أن الدخل يتحقق نتيجة استخدام الأصول في

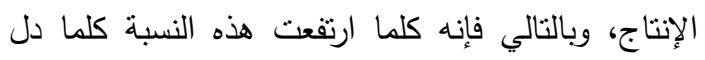
على كفاءة استخدام هذه الأصول والذي بعني قدرة أكبر على تحقيق الأرباح للمشروع.

\section{ج- صافي العائد الى حقوق الملكية= (صافي الربح 100* أو الخسارة /حقوق الملكية)}

وتقيس هذه النسبة مقدار العائد الناتج من استثمار حقوق الملكية بالمنشأة، أي تعبر عن العائد الذي يحققه

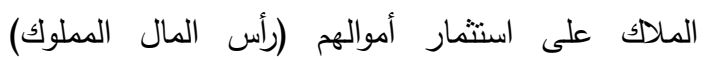
بالمشروع، وتعتبر من أهم نسب الربحية حيث أنه بناءاً

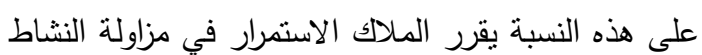
أو تحويل الأموال الى استثمارات أخرى تحقق عائداً مناسباً وكذلك يعتبر مؤشراً لإحداث تغييرات أساسية في سياسات المنشأة أو مديريها.

2- مؤشر الكفاءة الإنتاجية: (ويتم حسابه من (المعادلة التالية) معدل دوران صافي رأس المال المستثر = المبيعات / صافي رأس المال المستثر 3- مؤثر الكفاءة التسويقية: (ويتم حسابه من المعادلة التالية)

معدل دوران صافي رأس المال العامل= المبيعات /

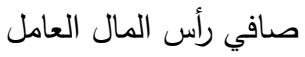
وتقيس هاتين النسبتين كفاءة استخدام رأس المال العامل والمستثمر في تحقيق مبيعات، ويشير تزايدهما من

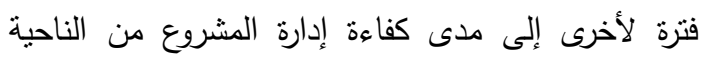

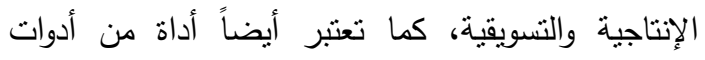
الرقابة على عمليات الإنتاج والتكاليف.

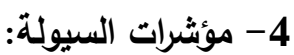

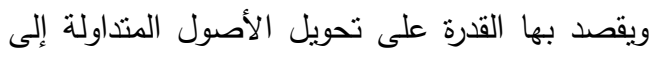
نقدية من أجل تغطية الخصوم المتداولة (الالتزامات 


$$
\text { مصادر البيانات: }
$$

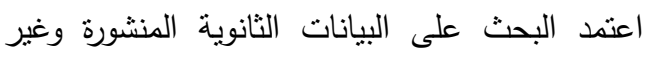

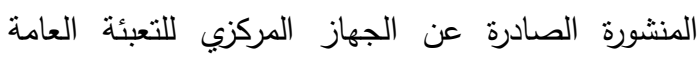

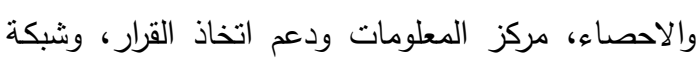

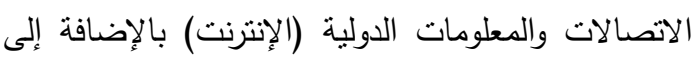

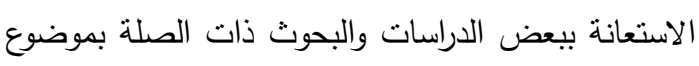
ومنهجية البحث.

$$
\text { نتائج البحث: }
$$

أولاً: تطور قيمة الإنتاج الفعلي والطاقات العاطلة والمتاحة الحقيقية1 لصناعة المنتجات الغذاتئية الفعي ولطاتئات العاطية لكل من القطاع العام والاعمال العام والقطاع الخاص خلال الفترة (2007/2006:(2014/2013

- يتضح من بيانات جدول رقم (1) أن قيمة الإنتاج

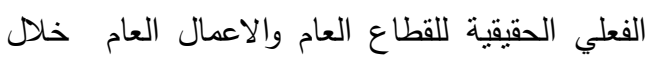
عام (2007/2006) بلغت نحو 47.4 مليون جنيه تزايدت لتصل إلى نحو 93.7 مليون جنيه خلال عام

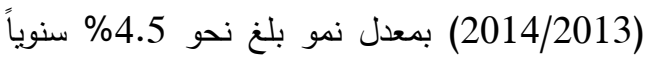
وبمنوسط بلغ نحو 60.6 مليون جنيه خلال الفترة

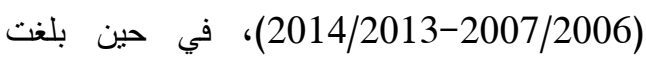
الطاقات العاطلة لنفس القطاع نحو 26 مليون جنيه

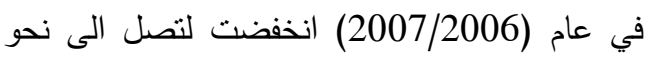
10 مليون جنيه خلال عام (2014/2013) بمنوسط

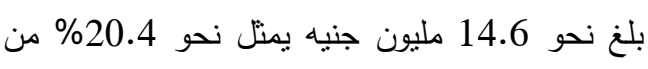
متوسط إجمالي الطاقة المتاحة والتي بلغت نحو 75 ندئ ندو مليون جنيه كمتوسط للفنزة (2007/2006. 2014/2013 - كما يتضح من بيانات جدول رقم (1) أيضا أن قيمة الإنتاج الفعلي الحقيقية في قطاع صناعة صلاعة المنتجات الغذائية بالقطاع الخاص قد بلغ نحو 109.3 مليون

1 تم تقدير القيم الحقيقية = القيم الجارية/ الرقم القياسي العام للصناعات التحويلية (سنة الاساس الجندارية 2002) لتلافي الآثار
ج- متوسط نصيب جنيه المبيعات من تكاليف الذدمات التسويقية= تكاليف الخدمات التسويقية / المبيعات.

دـ - متوسط نصيب جنيه المبيعات من تكلفة الخدمات الإدارية وإلتمويلية=تكلفة الخدمات الإدارية والتمويلية

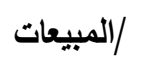

وتقيس النسبتنين السابقتين مدى التتاسب بين تكاليف

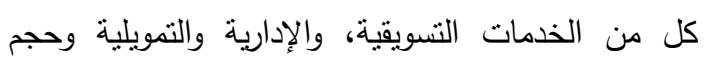

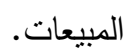
هـ- إنتاجية جنيه المواد الخام = (المبيعات/قيمة 100* مستلزمات الإنتاج)

وتعبر هذه النسبة عن كفاءة الإدارة في استخلال الموارد والإمكانات المتاحة لديها. 6- نسب الرفع المالي (المديونية):

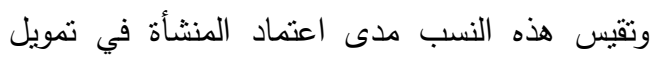

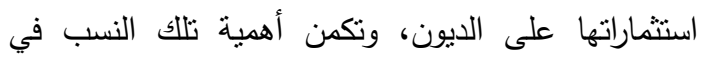

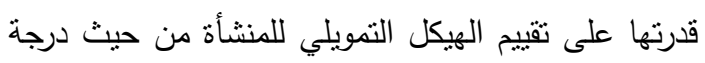
اعتمادها على مصادر التمويل داخلية كانت أم خارجية. أ- اجمالي الالتزامات الى اجمالي الأصول=إجمالي الخصوم/إجمالي الأصول وتوضح هذه النسبة مدى قدرة المنشأة على سداد الادول التزاماتها الجارية وسداد القروض. وكلما انخفضت هذه النسبة كان ذلك أفضل من وجهة نظر كل من المقرضين والمستثرين الخارجيين.

ب-إجمالي الالتزامات إلى حقوق الملكية=إجمالي الخصوم/إجمالي حقوق الملكية ينتم الحصول على أصول المنشأة من أموال أصحاب

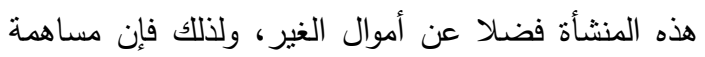
أصحاب المنشأة بالجزء الأكبر من هذه الأهن الأموال يكون

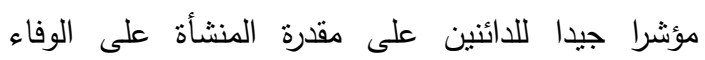
بالتزاماتها، وبذلك تثتير هذه النسبة إلى مدى مساهمة الغير في أموال المنثأة بالمقارنة إلى مساهمة أصحاب التئي

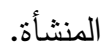


وعلى الرغم من انخفاض الطاقات العاطلة في القطاع

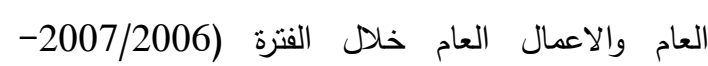

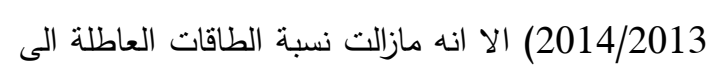

إجمالي الطاقات المتاحة في القطاع العام اعلى منها في

القطاع الخاص حيث مثلت حوالي 20.4\% من إجمالي

الطاقات المناحة في القطاع العام مقارنة ب 13 \% فقط حن

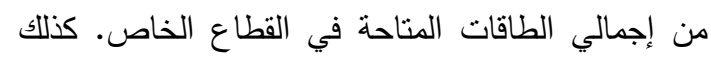

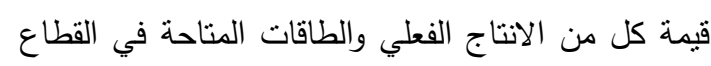

الخاص اعلى من مثيلاتها في القطاع العام والاعمال

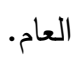

جنيه خلال عام (2007/2006) نزايدت لتصل الى نحو 284.9 مليون جنيه خلال عام (2014/2013)

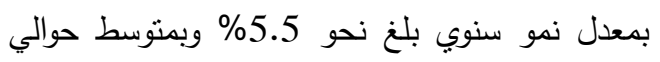

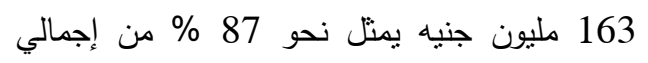
الطاقات المتاحة، كما شهدت الطاقات العاطلة نزايداً خلال الفترة سالفة الذكر حيث بلغت حوالي 11 مليون

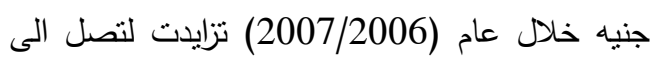
حوالي 39 مليون جنيه في عام (2014/2013)

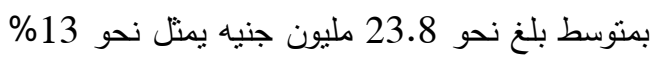
من متوسط إجمالي الطاقات المتاحة والتي بلغت بلت بلت بلت

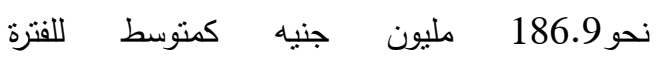
.2014/2013-2007/2006)

جدول رقم (1): تطور قيمة الإنتاج الفعلي والطاقات العاطلة وإلمتاحة الحقيقية للمنتجات الغذائية لكل من القطاع العام (القيمة بالمليون جنيه)

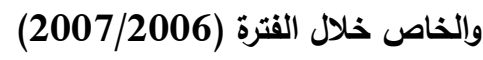

\begin{tabular}{|c|c|c|c|c|c|c|c|c|c|c|}
\hline \multicolumn{5}{|c|}{ القطاع الخاص } & \multicolumn{5}{|c|}{ القطاع العام والاعمال العام } & \multirow{3}{*}{ السنة } \\
\hline الفعلي \% & العاطلة\% & الطاقات & الطاقات & الإنتاج & الفعلي \% & العاطلة\%\% & الطاقات & الطاقات & الإنتاج & \\
\hline ا : المتاحة & : المتاحة: & المتاحة & العاطلة & الفعلي - الفي & المتاحة: & المتاحة & المتاحة المة & العاطلة & الفعلي & \\
\hline 90.8 & 9.2 & 120.35 & 11.1 & 109.25 & 64.5 & 35.5 & 73.39 & 26.02 & 47.37 & $2007 / 2006$ \\
\hline 87.1 & 12.9 & 145.75 & 18.82 & 126.94 & 75.3 & 24.7 & 63.1 & 15.57 & 47.53 & 2008/2007 \\
\hline 79.5 & 20.5 & 150.95 & 30.87 & 120.08 & 75.1 & 24.9 & 55.05 & 13.69 & 41.37 & $2009 / 2008$ \\
\hline 86.2 & 13.8 & 152.55 & 21.09 & 131.47 & 76.2 & 23.8 & 70.57 & 16.81 & 53.76 & 2010/2009 \\
\hline 86.9 & 13.1 & 161.63 & 21.21 & 140.43 & 83.8 & 16.2 & 66.86 & 10.81 & 56.05 & $2011 / 2010$ \\
\hline 88.7 & 11.3 & 193.55 & 21.94 & 171.61 & 84.2 & 15.8 & 80.95 & 12.82 & 68.13 & 2012/2011 \\
\hline 89.3 & 10.7 & 246.72 & 26.37 & 220.35 & 87.6 & 12.4 & 87.39 & 10.88 & 76.51 & 2013/2012 \\
\hline 88 & 12 & 323.86 & 39 & 284.86 & 90.3 & 9.7 & 103.77 & 10.03 & 93.74 & 2014/2013 \\
\hline 87.05 & 12.95 & 186.92 & 23.8 & 163.12 & 79.63 & 20.37 & 75.14 & 14.58 & 60.56 & المتوسط \\
\hline - & - & 5.4 & 4.9 & 5.5 & - & - & 2.7 & -4.7 & 4.5 & 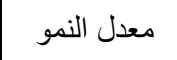 \\
\hline
\end{tabular}

المصدر: جمعت وحسبت من الجهاز المركزي للتعبئة العامة والاحصاء، النشرة السنوبة للإنتاج الفعلي والطاقة العاطلة والمخزون من

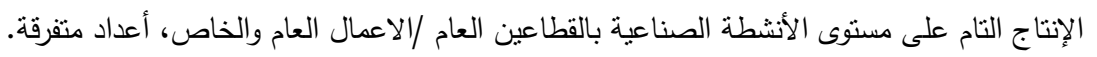


الكهربائي، وغياب العمالة وانخفاض مستوى كفاءتهم، كذلك قد نعود الى أسباب مرتبطة بظروف السوق مثل: ظروف المنافسة، سوء تقدير حجم الطلب خلال مراحل تقييم المشروعات والاعداد لها.

ويتضح من بيانات جدول رقم (2) أنه على الرغم من

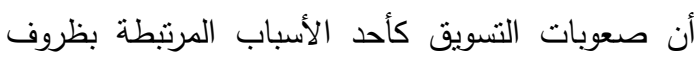

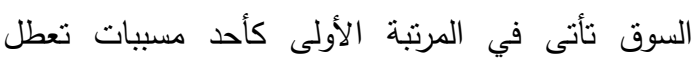
الطاقات الإنتاجية في قطاع صناعة المنتجات الغذائية في

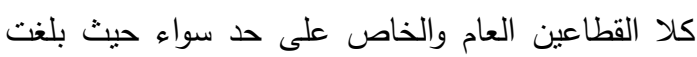

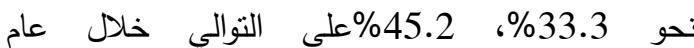
(2007/2006) من إجمالي قيمة الطاقات العاطلة خلا خلاكل نفس العام، نزايدت لتصل الى نحو 79.5\%، 49.2\%

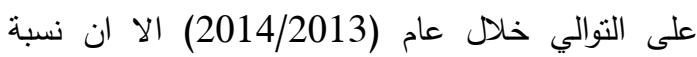
الزيادة بلغت نحو 46.2\% في القطاع العام والاعمال العام، بينما بلغت فقط نحو 4\% في القطاع الخاص مما لهاع

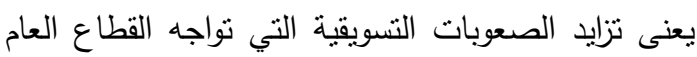

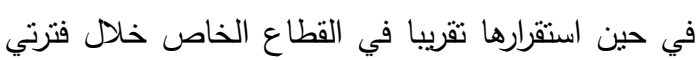

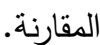

ثانياً: التوزيع النسبي لأسباب ظهور الطاقات العاطلة لصناعة المنتجات الغذائية لكل من لابناب القطاع العام والاعمال العام والقطاع الخاص

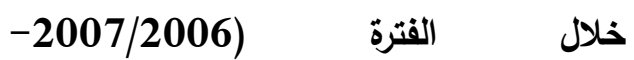
:(2014/2013

تمثل الطاقات العاطلة في القطاع الصناعي واحدة من أهم الظواهر الاقتصادية التي يترتب عليها آثار سلبية جمة على أداء هذا القطاع (وذلك إذا ما قورنت بالمستويات القابلة للتحقق في ضوء الطاقات الإنتاجية المتاحة). وتتمثل خطورتها في تأثنراتها المنعكسة على باقي قطاعات الاقتصاد القومي مما يزبد من تدهور معدلات النمو

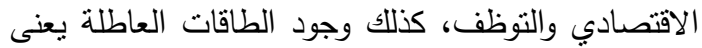
وجود جانب من الأصول الإنتاجية الثابتة غير مستغل وجل استغلالًا كاملاً والذي يمثل هدراً في موارد الدول النامية التي تعاني من نقص المدخرات المحلية اللازمة لتكوين رأس المال الثابت. وتقسم الأسباب المباشرة لظهور الطاقات العاطلة الى أسباب ذات طبيعة فنية مثل: مدى توافر وملائمة المواد الخام، السلع الوسيطة المستخدمة، انقطاع التيار

جدول رقم (2): التوزيع النسبي لأسباب ظهور الطاقات العاطلة لصناعة المنتجات الغذائية لكل من القطاع العام /لاعمال العام والقطاع الخاص خلال الفترتين (2007/2006-2013/2012)

\begin{tabular}{|c|c|c|c|c|}
\hline \multicolumn{2}{|c|}{ القطاع الخاص } & \multicolumn{2}{|c|}{ القطاع العام والاعمال العام } & 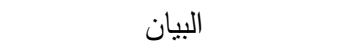 \\
\hline $2014 / 2013$ & $2007 / 2006$ & $2014 / 2013$ & $2007 / 2006$ & أسباب ظهور الطاقات العاطلة \\
\hline 49.2 & 45.2 & 79.5 & 33.3 & صعوبات التسويق \\
\hline 13.4 & 26.6 & 0.6 & 15.7 & نقص المواد الخام \\
\hline 3.2 & 5.3 & 0.3 & - & نقص قطع الغيار \\
\hline 4.8 & 3.5 & 10.8 & - & نقص وتغيب العمال \\
\hline 29.4 & 19.4 & 8.8 & 51 & أخرى(") \\
\hline
\end{tabular}

المصدر: جمعت وحسبت من الجهاز المركزي للتعبئة العامة والاحصاء، النشرة السنوية للإنتاج الفعلي والطاقة العاطلة والمخزون من الإنتاج التام على مستوى الأنشطة الصناعية بالقطاعين العام /الاعمال العام والخاص، أعداد متفرقة. 


\section{$-2007 / 2006)$ \\ خلال الفترة \\ :(2014/2013}

يوضح جدول رقم (3) بالبحث، وجدول رقم (2) بالملاحق تطور اهم معالم قطاع المنتجات الغذائية في قطاع الاعمال العام خلال الفترة (2007/20062014/2013) ما يلي:

- تزايد قيمة الأصول لقطاع صناعة المنتجات الغذائية التابع لقطاع الاعمال العام من نحو 10.4 مليار جنيه عام (2007/2006) الى حوالى 15.9 مليار جنيه في عام (2014/2013) بمعدل نمو بلغ نحو 2.8 \% سنوياً بمنوسط بلغ نحو 12.8 مليار جنيه يمنل نحو 17.4\% من متوسط قيمة الأصول للصناعات التحويلية بقطاع الاعمال العام خلال فترة الدراسة. كذلك تزايدت قيمة الخصوم لقطاع صناعة المنتجات الغذائية التابع لقطاع الاعمال العام من نحو 10.5 مليار جنيه عام (2007/2006) الى حوالي 16 مليار جنيه في عام (2014/2013) بمعدل نمو بلغ نحو 2.9 \% سنوياً بمتوسط بلغ نحو 12.8 مليار جنيه يمثل نحو 12.7\% من منوسط قيمة الخصوم للصناعات التحويلية بقطاع الاعمال العام خلال فترة

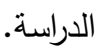
- تزايد قيمة حقوق الملكية3 لقطاع صناعة المنتجات الغذائية من نحو 2.3 مليار (2007/2006) الى نحو 4.3 مليار جنيه عام (2014/2013) بزيادة تقدر بنحو 2 مليار جنيه وبمنوسط بلغ نحو 2.7 مليار جنيه يمتل نحو 5.2\% من متوسط قيمة حقوق الملكية للصناعات التحويلية بقطاع الاعمال العام خلال فنزة الدراسة.

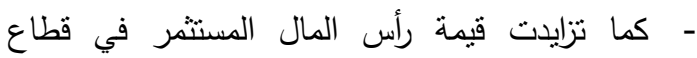
صناعة المنتجات الغذائية التابع لقطاع الاعمال العام

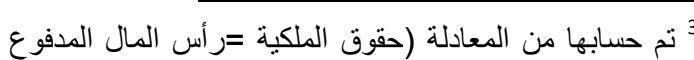

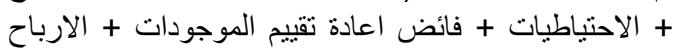

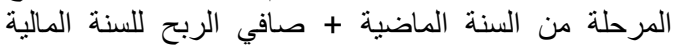
الحالية) - مركز معلومات قطاع الاعمال العام - قائمة العالية المركز المالي لشركتي قها، ادفينا.
بينما يأتي نقص المواد الخام كأحد الأسباب الفنية

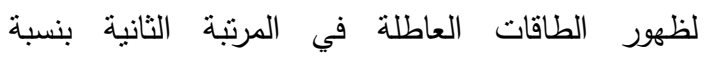

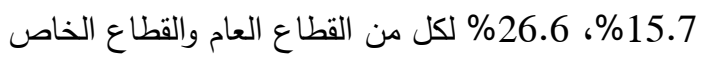
على النوالي خلال عام (2007/2006) تناقصت لتصل الى 0.6\%، 13.4\% على التوالي خلال عام

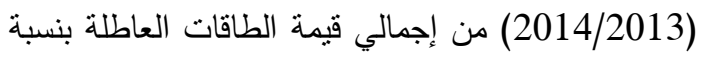
نقص بلغت نحو 15\%، 13.2\% في كلا القطاعين العام

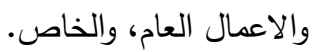
في حين نزايدت نسبة كل من نقص قطع الغيار، ونقص وتغيب العمال في القطاع العام والاعمال العام حيث انعدمت خلال عام (2007/2006) بينما وصلت ولفي الاعطال نسبة النقص الى 0.3\%، 10.8\% من إجمالي قيمة الطاقات العاطلة على التوالي خلال عام (2014/2013)، في حين منتل قدم الآلات وعمرات وصيانة غير عادية

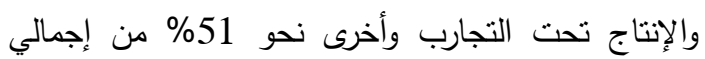
الطاقات العاطلة خلال عام (2007/2006) نتاقصت لتصل الى نحو 8.8\% خلال عام (2014/2013) بنسبة نقص بلغت حوالي 42.2\%

كذلك تتاقصت نسبة نقص قطع الغيار كأحد اسباب ظهور الطاقات العاطلة في القطاع الخاص حيث بلغت نحو 5.3\% عام (2007/2006) نتاقصت لتصل الى نحو 3.2\% في عام (2014/2013)، في حين نزايدت

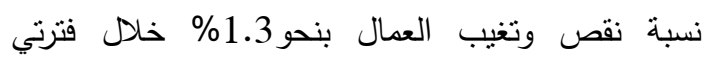

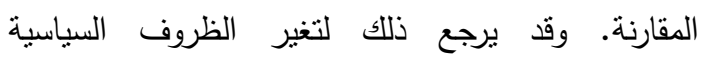

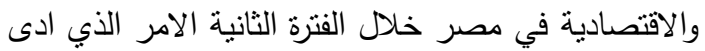
الى غياب الأيدي العاملة الماهرة في كلا القطاعين العام والخاص على حد سواء.

ثالثاً: تطور أهم معالم قطاع المنتجات الغذائية بكل

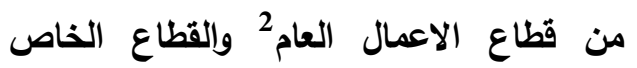

22 بعد صدور القانون رقم 203 لعام 1991 اصبحت الثركات القابضة تحل محل هيئات القطاع العام وأصبح دورها الأساسي هو الاستثمار. 


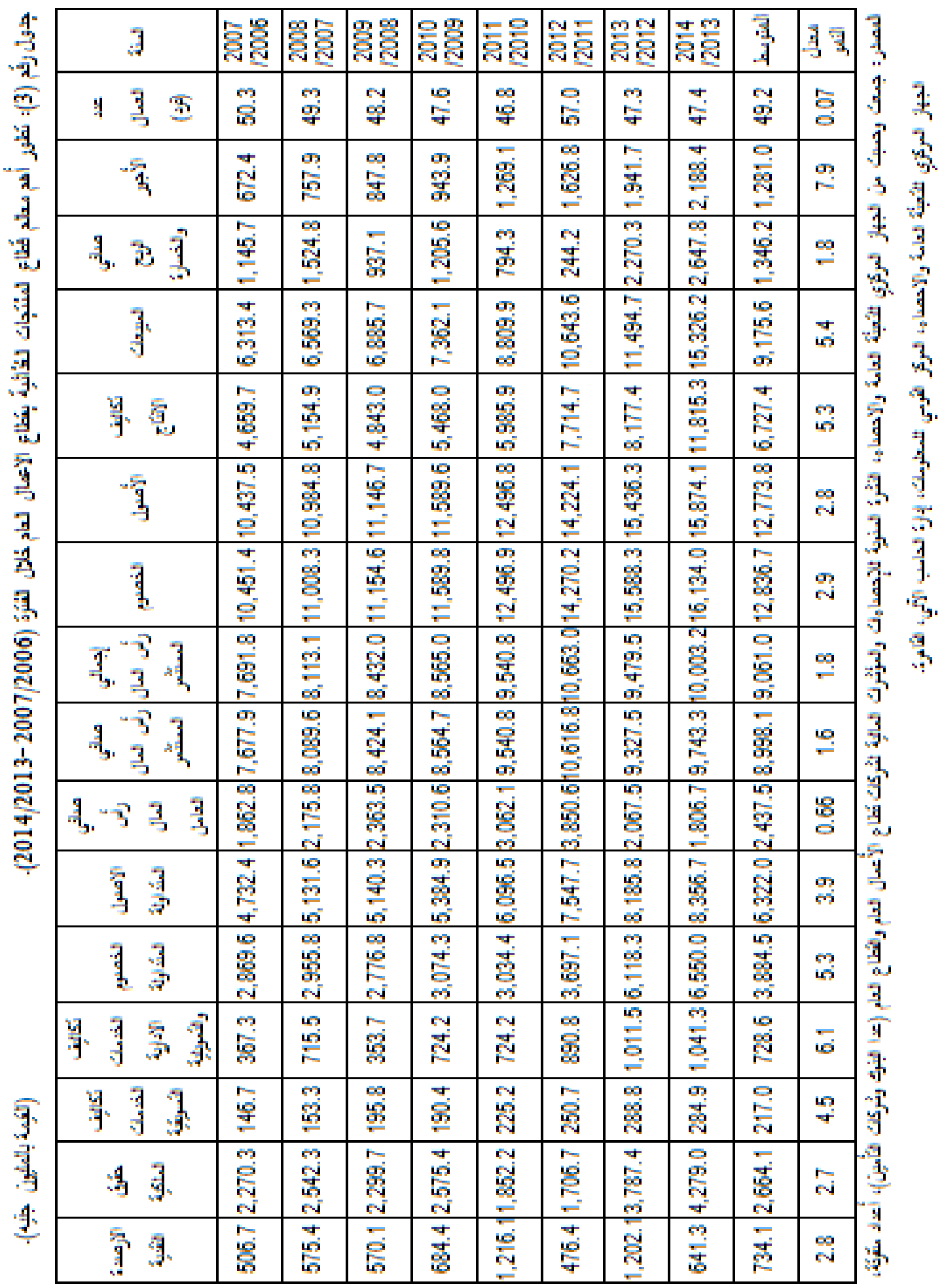


قيمة مبيعات قطاع الصناعات التحويلية والبالغة نحو

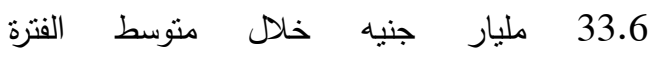
.2014/2013-2007/2006)

- تتاقص عدد العمال في قطاع صناعة المنتجات الغذائية التابع لقطاع الاعمال العام من حوالي 50 ألف عامل عام (2007/2006) الى حوالي 47 ألف عامل في عام (2014/2013) بمنوسط بلغ نحو 49 ألف عامل يمنلون نحو 22.6\% من إجمالي عدد

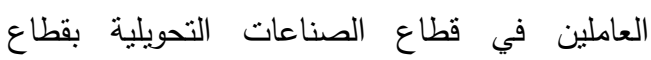

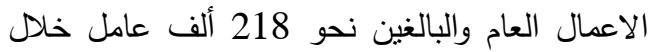
منوسط فترة الدراسة. - في حين تزايدت قيمة الأجور في قطاع صناعة المنتجات الغذائية من حوالي 672 مليون جنيه عام (2007/2006) الى حوالي 2.2 مليار جنيه في عام

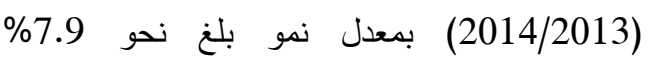

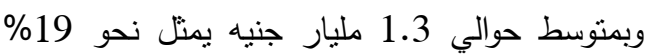
من متوسط الاجور لقطاع الصناعات التحويلية بقطاع الاعمال العام خلال فترة الدراسة سالفة الذكر . ويوضح جدول رقم (4) بالبحث، وجدول رقم (4) بالملاحق نطور اهم معالم قطاع المنتجات الغذائية في

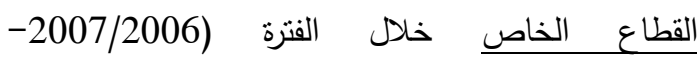
2014/2013 ما يلي:

- نزايد قيمة الأصول لقطاع صناعة الهنتجات الغذائية بالقطاع الخاص من نحو 67 مليار جنيه عام كحد أدنى لاصى

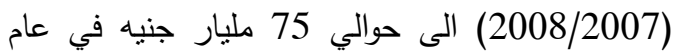
0.6 (2014/2013) كحد أقصى بمعدل نمو بلغ نحولي

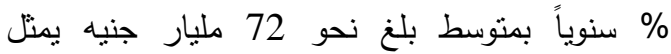
نحو 7.7 \% من منوسط قيمة الأصول للصناعات التحويلية بالقطاع الخاص والبالغة نحو 94 مليار جنيه كنتوسط للفترة سالفة الذكر .

- كذلك تزايدت قيمة الخصوم لقطاع صناعة المنتجات الغذائية بالقطاع الخاص من نحو 72 مليار جنيه عام (2008/2007) الى حوالي 80 مليار جنيه في عام (2014/2013) بمعدل نمو بلغ نحو 0.5 \% سنوياً
من حوالي 7.7 مليار جنيه خلال عام (2007/2006) الى حوالي 10 مليار جنيه في عام (2014/2013) بمتوسط بلغ نحو 9.1 مليار جنيه مثل نحو 14.8\% من متوسط قيمة رأس المال المستثمر في قطاع الصناعات التحويلية والبالغ نحو لماتل 61 مليار جنيه وقد أوضحت معادلة النمو التزايد المعنوي احصائياً لقيمة رأس المال المستثر في قطاع

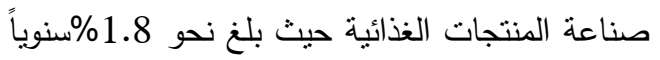

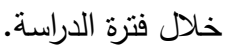
- تززايدت قيمة الاصول المتداولة من نحو 4.7 مليار جنيه عام (2007/2006) الى نحو 8.4 مليار جنيه

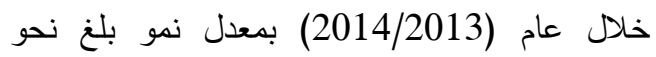

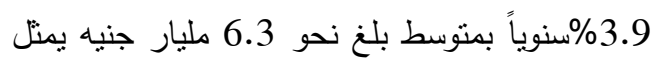
نحو 17.6\% من منوسط قيمة الاصول المتداولة لقطاع الصناعات التحويلية خلال فترة الدراسة. - كذللك تزايدت قيمة الخصوم المتداولة من نحو 2.9 مليار جنيه عام (2007/2006) الى نحو 6.6 مليار جنيه خلال عام (2014/2013) بمعدل نمو بلغ نحو

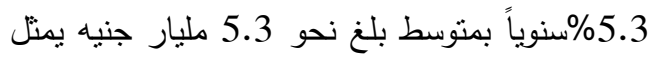
نحو 9.4\% من متوسط قيمة الخصوم المتداولة

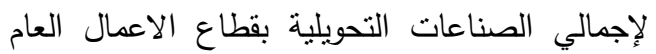
خلال فتزة الدراسة. وعلى الرغم من تزايد قيمة الاصول المتداولة عن قيمة

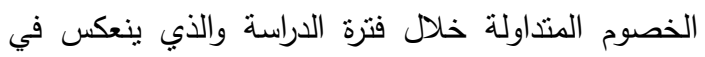
تزايد رأس المال العامل مما يعكس كفاءة عنصر الادارة في قطاع الاعمال العام الا ان معدل نمو الاصول

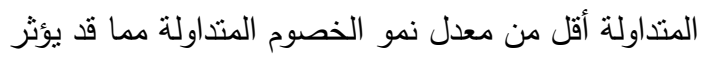
بالسلب على معدل نمو صافي رأس المال العامل مستقبلاً حيث بلغ نحو 0.66\% فقط خلال فترة الدراسة. - تزايدت قيمة مبيعات قطاع صناعة المنتجات الغذائية التابع لقطاع الاعمال العام من نحو 6.3 مليار جنيه عام (2007/2006) الى حوالي 15.3 مليار في عام

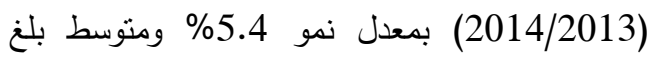
نحو 9 مليار جنيه يمنل حوالي 27.3\% من متوسط بمد 


\begin{tabular}{|c|c|c|c|c|c|c|c|c|c|c|c|}
\hline 3 & 홍요 & 홍 & 얄 & 울올 & 훙울 & 혈 & 형 & 훌 & 3 & 可夏, & 3 \\
\hline 435 & 安 & 8 & $\frac{9}{9}$ & 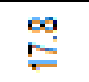 & 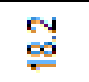 & $\begin{array}{l}0 \\
0 \\
0\end{array}$ & 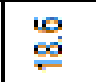 & $\frac{9}{2}$ & $\overline{\bar{\alpha}}$ & 8 & \\
\hline$=5$ & 蒲 & $\frac{6}{8}$ & 8 & 8 & $\begin{array}{l}0 \\
\frac{8}{6} \\
\frac{6}{6}\end{array}$ & 8 & 8 & $\frac{6}{8}$ & 离 & $\mathrm{m}$ & 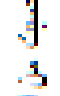 \\
\hline$\frac{3}{3}, \frac{1}{3}$ & 焉 & $\begin{array}{l}6 \\
5 \\
0\end{array}$ & 웋 & 붕 & 8 & 홍 & 's: & 형 & $\mathbf{g}$ & $\frac{9}{7}$ & 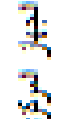 \\
\hline 3 & 8 & च & 5 & 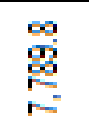 & $\begin{array}{l}\text { o } \\
\text { 尌 } \\
\text { क }\end{array}$ & 点 & 点 & $\begin{array}{l}\frac{9}{5} \\
5 \\
5 \\
8\end{array}$ & $\mathrm{~B}$ & $\frac{8}{8}$ & $\begin{array}{l}7 \\
3\end{array}$ \\
\hline 第" & $\begin{array}{l}6 \\
5 \\
5 \\
5\end{array}$ & $\begin{array}{l}0.9 \\
8 \\
8 \\
8\end{array}$ & $\sum_{i}$ & $\begin{array}{l}9 \\
\frac{9}{5} \\
0 \\
0\end{array}$ & 8 & 量 & 8 & 愛 & 8 & 8 & $A$ \\
\hline & $\begin{array}{l}10 \\
10 \\
5 \\
5\end{array}$ & $\begin{array}{l}8 \\
8 \\
8 \\
8 \\
8\end{array}$ & ? & $\begin{array}{l}9 \\
\frac{9}{5} \\
5\end{array}$ & 8 & 8 & 高 & 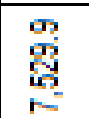 & 8 & 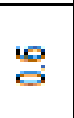 & 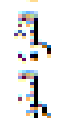 \\
\hline & 8 & S & s & 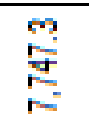 & sis & 8 & 8 & $\begin{array}{l}\text { 量 } \\
\text { 喜 } \\
0\end{array}$ & $\frac{10}{5}$ & 8 & . \\
\hline$\frac{1}{3}$ & 8 & 8 & 8 & 8 & 8 & 8 & $\begin{array}{l}6 \\
8 \\
8\end{array}$ & 站 & 8 & $\bar{d}$ & 1 \\
\hline 量, 3 & $\begin{array}{l}3 \\
8 \\
8 \\
5\end{array}$ & 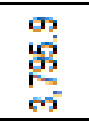 & $\begin{array}{l}5 \\
8 \\
8\end{array}$ & 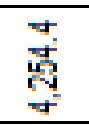 & $\begin{array}{l}9 \\
8 \\
8 \\
8\end{array}$ & 8 & 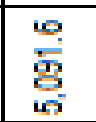 & $\frac{9}{8}$ & 8 & $\mathbb{d}$ & $\begin{array}{l}3 \\
7 \\
y\end{array}$ \\
\hline$n_{3}-3 \quad \frac{3}{5}$ & $\frac{9}{8}$ & $\begin{array}{l}\text { 要 } \\
\end{array}$ & 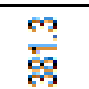 & $\bar{s}$ & $\frac{1}{81}$ & 8 & 8 & 㝵 & 8 & is & s. \\
\hline $3 \frac{5}{3}$ & 学 & $\frac{5}{9}$ & 8 & $\begin{array}{l}\mathrm{n} \\
\mathrm{v} \\
\mathrm{m}\end{array}$ & 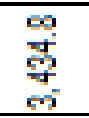 & 影 & 8 & 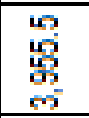 & 焉 & 을 & $\begin{array}{l}\frac{3}{3} \\
3 \\
3\end{array}$ \\
\hline 量需 & $\begin{array}{l}9 \\
8 \\
8\end{array}$ & $\begin{array}{c}\mathrm{g} \\
\mathrm{g}\end{array}$ & $\begin{array}{c}5 \\
5 \\
5 \\
5\end{array}$ & 5 & $\frac{9}{9}$ & 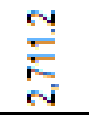 & 8 & $\begin{array}{l}9 \\
\text { 遙 } \\
\text { m } \\
\end{array}$ & $\begin{array}{l}3 \\
3 \\
8\end{array}$ & 8 & 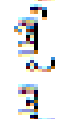 \\
\hline 青 & 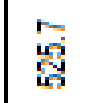 & 峦 & $\frac{8}{8}$ & $\frac{5}{9}$ & 8 & 章 & 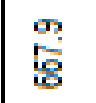 & y & 8 & \pm & $\frac{\pi}{4}$ \\
\hline 㸵 & 实 & 올 & 范 & 웅 & ⿶ㅗㅇ & 웅 & $\begin{array}{l}8 \\
8\end{array}$ & is & 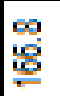 & $\frac{6}{8}$ & is \\
\hline 49 & $\begin{array}{l}5 \\
\mathrm{~g} \\
\mathrm{~g}\end{array}$ & $\begin{array}{l}8 \\
8 \\
8\end{array}$ & $\begin{array}{l}3 \\
8 \\
3\end{array}$ & 5 & $\frac{m}{8}$ & $\begin{array}{l}\text { 表 } \\
\text { s. }\end{array}$ & $\frac{3}{8}$ & 荘 & $\begin{array}{l}9 \\
8 \\
8 \\
5\end{array}$ & 8 & $\frac{3}{3}$ \\
\hline 군 & 농 & $\begin{array}{l}\text { \& } \\
8\end{array}$ & 5 & 옹 & $\begin{array}{l}8 \\
\text { 문 }\end{array}$ & 영 & $\begin{array}{l}\text { ำ } \\
6 \\
6\end{array}$ & sid & $\mathrm{B}$ & 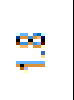 & 1 \\
\hline
\end{tabular}


• وبالرغم من تزايد قيمة الاصول المتداولة عن قيمة

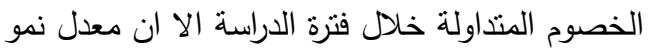
الاصول المتداولة أعلى من معدل نمو الخصوم المنداولة مما ينعكس في تزايد رأس المال العامل والذي يعكس كفاءة عنصر الادارة في القطاع الخاص حيث بلغ معدل نمو صافي رأس المال العمل بنسبة 5.7 \% خلال منوسط فترة الدراسة. - - تزايدت قيمة مبيعات قطاع صناعة المنتجات الغذائية التابع للقطاع الخاص من نحو 4.6 مليار جنيه عام مليعات (2007/2006) الى حوالي 8.6 مليار في عام (2014/2013) بمعدل نمو 4.2 \% ومنوسط بلغ

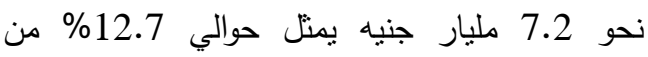
متوسط قيمة مبيعات قطاع الصناعات التحويلية بالقطاع الخاص خلال الفترة (2014/2013) .(2014/2013

- تزايد عدد العمال في قطاع صناعة المنتجات الغذائية التابع بالقطاع الخاص من حوالي 16 ألف عامل عام (2007/2006) الى حوالي 19 ألف عامل في عام (2014/2013) بمنوسط بلغ نحو 18 ألف عامل

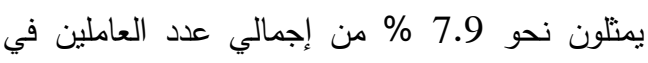
قطاع الصناعات التحويلية بالقطاع الخاص. كذلك نزايدت قيمة الأجور في قطاع صناعة المنتجات

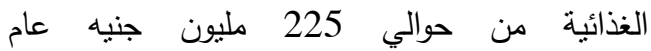
(2007/2006) الى حوالي 691 مليون جنيه في

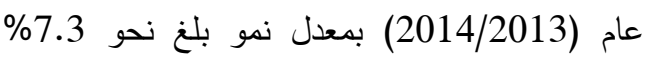

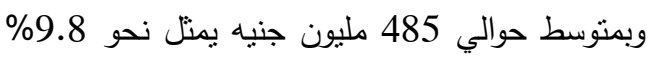
من متوسط الاجور لقطاع الصناعات التحويلية بالقطاع الخاص خلال فترة الدراسة سالفة الذكر.

رابعا: المؤشرات المالية لتقييم أداء قطاع صناعة المنتجات الغذائية بكل من قطاع الاعمال العام والقطاع الخاص خلال الفترة (2007/2006:(2014/2013

تعتبر الاحصاءات والمؤشرات المالية المرآة التي
بمتوسط بلغ نحو 77 مليار جنيه يمثل نحو 7.65\%

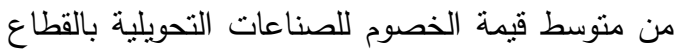
الخاص والبالغة نحو 100.8 مليار جنيه كمنوسط لفترة

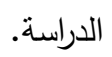

- تتاقص قيمة حقوق الملكية لقطاع صناعة المنتجات الغذائية من نحو 38.4 مليار (2007/2006) كد أقصى الى نحو 31.4 مليار جنيه عام (2013/2012) كحد أدنى بانخفاض يقدر بنحو 7 مليار جنيه وبمتوسط بلغ نحو 36 مليار جنيه يمثل نحو 6.4\% من منوسط قيمة حقوق الملكية

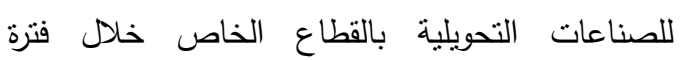

$$
\text { الدراسة. }
$$

- تزايدت قيمة رأس المال المستثر في قطاع صناعة المنتجات الغذائية التنابع للقطاع الخاص من حوالي 4.2 مليار جنيه خلال عام (2007/2006) الى حوالي 5.7 مليار جنيه في عام(2014/2013) بمتوسط بلغ نحو 5 مليار جنيه منل نحو 7\% من من منوسط قيمة رأس المال المستثر في قطاع الصناعات التحويلية والبالغ نحو 70 مليار جنيه وقد أوضحت معادلة النمو التزايد المعنوي احصائياً لقيمة رأس المال المستثر في قطاع المنتجات الغذائية حيث بلغ نحو 2.1\%سنوياً خلال فترة الدراسة. - تزايدت قيمة الاصول المنداولة من نحو 3 مليار جنيه عام (2007/2006) الى نحو 4 مليار جنيه خلال عام ندام (2014/2013) بمعدل نمو بلغ نحو 1.6 \%سنوياً بمتوسط بلغ نحو 3.4 مليار جنيه يمثل نحو 7.5 \% من بن

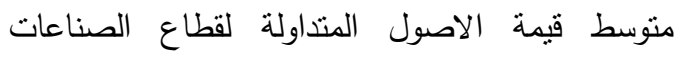
التحويلية خلال فتزة الدراسة.

- كذلك نزايدت قيمة الخصوم المنداولة من نحو 2.9 مليار جنيه عام (2007/2006) الى نحو 3.5 مليار جنيه خلال عام (2014/2013) بمتوسط بلغ نحو 2.95 .3 مليار جنيه يمثل نحو 9.5\% من منوسط قيمة

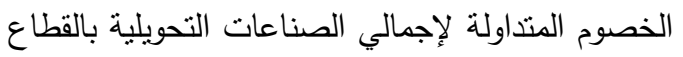

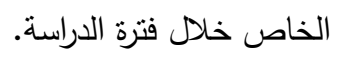


الدراسة. في حين نزايدت هذه النسبة لقطاع صناعة

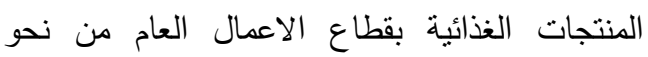

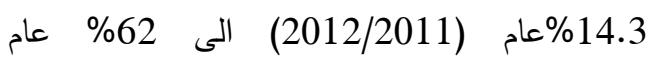

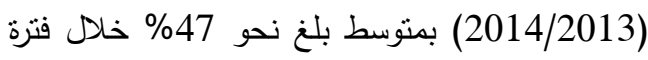

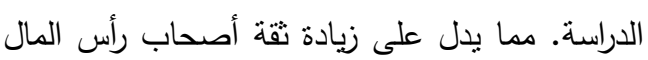

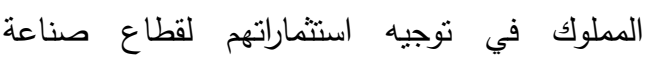

المنتجات الغذائية بقطاع الاعمال العام عن مثيله

$$
\text { بالقطاع الخاص. }
$$

\section{2- 20 - مؤشر الكفاعة الإنتاجية:}

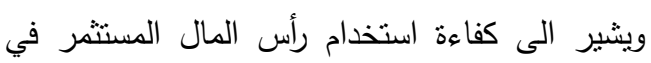

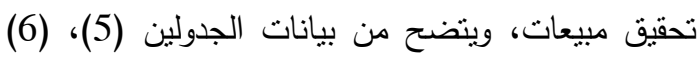

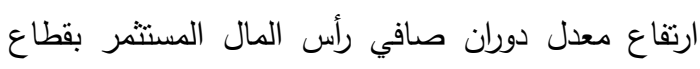
صناعة المنتجات الغذائية في القطاع الخاص عن منيله

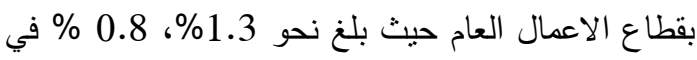
عام (2007/2006) على النوالي نزايد ليصل الى نحو الحو

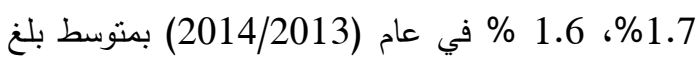
نحو 1.6 \% ، 1 \% \% خلال فتزة الدراسة. مما يعنى تزايد كفاءة القطاع الخاص في استخدامه لرأس المال المستثر

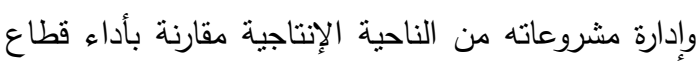
الاعمال العام خلال فترة الدراسة.

\section{3-مؤشر الكفاءة التسويقية:}

ويثير الى كفاءة استخدام رأس المال العامل في تحقيق مبيعات ، ويتضح من بيانات نفس الجدولين السابقين ارتفاع معدل دوران صافى رأس المال العامل

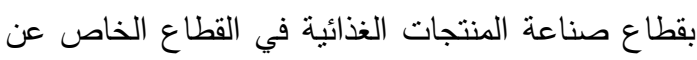

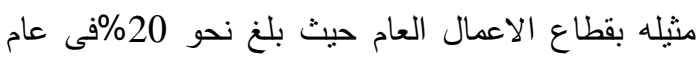
(2007/2006) في القطاع الخاص تزايد ليصل الى نحو نعام 24\% في عام (2010/2009) انخفتت بعد ذلك لتصل

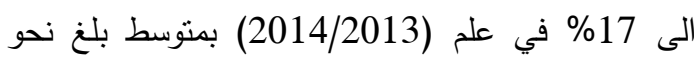

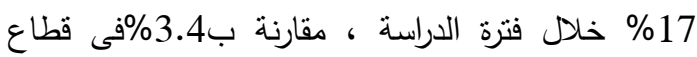
الاعمال العام في عام (2007/2006) والذى تزايد ليصل الى نحو 8.5 \% في عام (2014/2013) بمتوسط بلغ نحو 4\% خلال فترة الدراسة، الامر الذي كي
تعكس المركز المالي لنشاط الثركات الاتتاجية في فترة

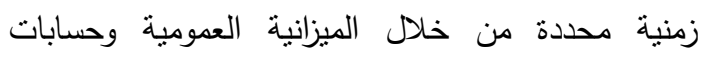
النتيجة.

1- مؤشرات الريحية:

وتوضح مدى قدرة المشروع على تحقيق الارباح من موندرات الريحئ

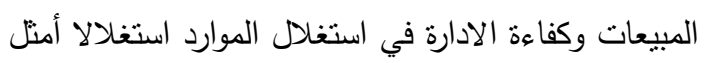
لتحقيق الارباح، ويتضح من بيانات الجدولين (5)، (6) ما يلي: أ- انخفاض نسبة صافي العائد الى الايرادات لقطاع صناعة المنتجات الغذائية بالقطاع الخاص من نحو لإئ

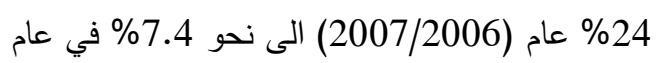
(2014/2013) بمتوسط بلغ نحو 13.4\% خلاد فترة الدراسة. بينما تذبذبت تلاك النسبة لقطاع صناعة

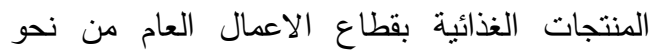
23\% كحد أقصى في عام (2008/2007) الى نحو لخد 2.3 \%كد أدنى في عام (2012/2011) بمنوسط في عام بلغ نحو 14.9\% خلال فترة الدراسة. ب-انخفاض نسبة صافي العائد الى الاصول لقطاع

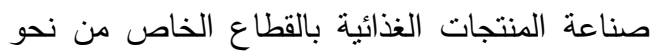

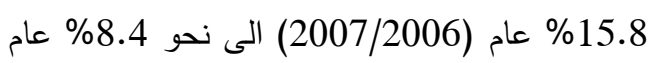
(2014/2013) بمتوسط بلغ نحو 12.2\% خلام الفترة (2007/2006-2014/2013). كذلك تراوحت تلك النسبة في قطاع صناعة المنتجات الغذائية بقطاع الاعمال العام من نحو 1.7\% كد أدنى عام

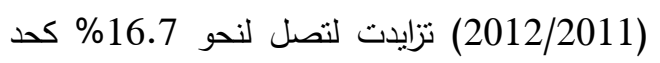
أقصى عام (2014/2013) بمتوسط بلغ نحو

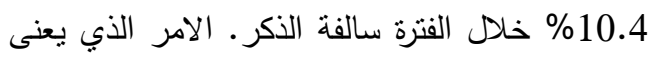

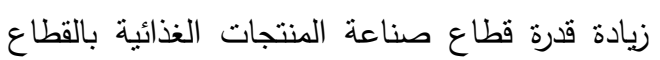
الخاص على تحقيق أرباح من أنشطته التتغيلية مقارنة بمثيله بقطاع الاعمال العام.

ج- انخفاض نسبة صافي الربح الى حقوق الملكية لقطاع صناعة المنتجات الغذائية بالقطاع الخاص من نحو لخدية

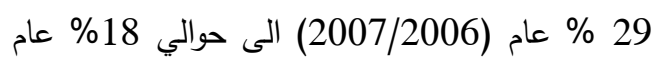
(2014/2013) بمتوسط بلغ نحو 24\%خلال فترة 


\begin{tabular}{|c|c|c|c|c|c|c|c|c|c|c|}
\hline \multicolumn{2}{|r|}{3} & $\begin{array}{l}\text { 号 } \\
\text { 点 }\end{array}$ & $\begin{array}{l}\text { 总 } \\
\text { 总 }\end{array}$ & 总 & $\begin{array}{l}\text { 용 } \\
\text { 웅 }\end{array}$ & 을 & 窎 & $\frac{\stackrel{0}{0}}{\stackrel{0}{\circ}}$ & 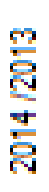 & 矛 \\
\hline \multirow{3}{*}{$\begin{array}{l}31 \\
3 \\
3 \\
3\end{array}$} & 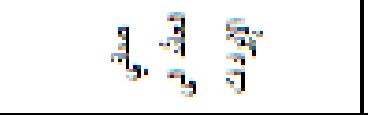 & 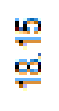 & $\overline{\mathrm{N}}$ & 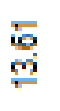 & 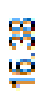 & 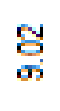 & $\stackrel{\mathbb{N}}{\mathrm{N}}$ & 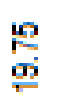 & 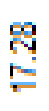 & $\begin{array}{l}\text { 最 } \\
\stackrel{5}{ \pm}\end{array}$ \\
\hline & , $\begin{array}{ll}\frac{3}{4} & 5 \\
3 & -3 \\
\end{array}$ & $\begin{array}{l}9 \\
\text { \% } \\
\stackrel{0}{\circ}\end{array}$ & 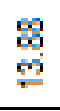 & $\underset{\infty}{\bar{y}}$ & 웡 & 瓷 & $\stackrel{2}{\rightleftarrows}$ & $\begin{array}{l}E \\
\pm\end{array}$ & $\begin{array}{l}\mathscr{0} \\
: 0 \\
\end{array}$ & $\stackrel{\text { gु }}{\circ}$ \\
\hline & 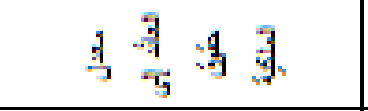 & 軠 & 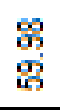 & $\begin{array}{l}\stackrel{2}{2} \\
\stackrel{9}{9}\end{array}$ & 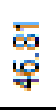 & $\begin{array}{l}\mathscr{B} \\
\mathbb{G} \\
\end{array}$ & 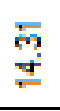 & $\begin{array}{l}\text { 岕 } \\
\text { g } \\
\text { 号 }\end{array}$ & 高 & $\begin{array}{l}\frac{2}{2} \\
\text { 守 }\end{array}$ \\
\hline 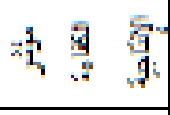 & 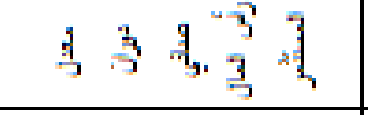 & ॐ & $\stackrel{5}{\infty}$ & $\stackrel{9}{\circ}$ & 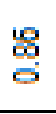 & 今̛ & $\stackrel{8}{-}$ & $\stackrel{尺}{\stackrel{2}{2}}$ & مै & $\stackrel{-}{\circ}$ \\
\hline 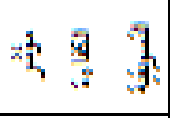 & $\frac{3}{3} 3$ & $\stackrel{g}{g}$ & है & $\stackrel{\bar{c}}{\sim}$ & $\stackrel{9}{\circ}$ & $\underset{\sim}{0}$ & $\stackrel{\mathscr{L}}{\mathrm{N}}$ & 总 & $\underset{\infty}{q}$ & \& \\
\hline \multirow{2}{*}{$\begin{array}{l}3_{1}^{1} \\
3 \\
3 \\
3\end{array}$} & & $\stackrel{8}{8}$ & $\stackrel{巳}{E}$ & $\stackrel{20}{\rightleftarrows}$ & $\stackrel{2}{\stackrel{2}{2}}$ & '̄ & म্ & 总 & 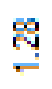 & $E$ \\
\hline & 3. 3 & $\stackrel{\infty}{6}$ & $\frac{9}{6}$ & $\overline{\mathrm{N}}$ & 중 & 웅 & $\stackrel{9}{0}$ & 송 & 응 & 송 \\
\hline \multirow{5}{*}{$\begin{array}{l}31 \\
3 \\
3 \\
39 \\
39\end{array}$} & 3 & $\stackrel{8}{\circ}$ & $\stackrel{8}{8}$ & $\stackrel{0}{\circ}$ & 志 & $\stackrel{?}{\circ}$ & $\frac{2}{5}$ & $\stackrel{+}{\stackrel{2}{0}}$ & 今) & 융 \\
\hline & 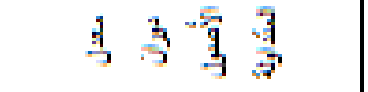 & $\stackrel{\mathrm{g}}{\mathrm{C}}$ & 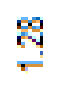 & $\stackrel{\text { ले }}{=}$ & $\stackrel{\mathrm{m}}{\mathrm{C}}$ & 品 & 巳 & 울 & $\mathscr{8}$ & g \\
\hline & 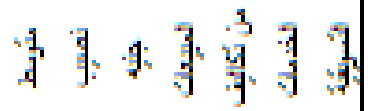 & 今 & 8 & 8 & 8 & 8 & 8 & 8 & 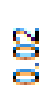 & 8 \\
\hline & 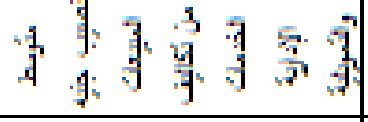 & \& & 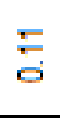 & 영 & 응 & 号 & 营 & 要 & '응 & 양 \\
\hline & 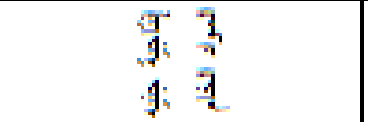 & 䐱 & $\begin{array}{l}\text { 寺 } \\
\text { 究 }\end{array}$ & $\stackrel{\infty}{\stackrel{q}{*}}$ & $\begin{array}{l}\text { 志 } \\
\text { 总 }\end{array}$ & 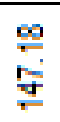 & 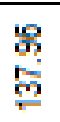 & 突 & 莺 & 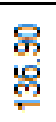 \\
\hline \multirow{2}{*}{$\begin{array}{l}3 \\
3 \\
3 \\
3 \\
3\end{array}$} & 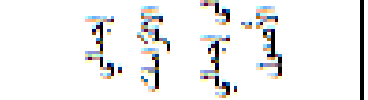 & 8 & 8 & $\stackrel{8}{-}$ & 8 & 8 & 8 & $\stackrel{5}{-}$ & $\stackrel{8}{0}$ & 8 \\
\hline & 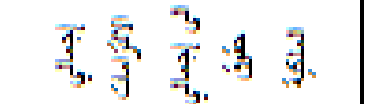 & $\begin{array}{l}8 \\
8\end{array}$ & $\stackrel{\text { fy }}{\mathrm{q}}$ & $\begin{array}{l}\text { 哭 } \\
\text { q }\end{array}$ & 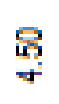 & 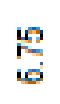 & 禺 & $\underset{+}{\stackrel{9}{*}}$ & $\underset{m}{E}$ & in \\
\hline
\end{tabular}


A comparative analysis study to evaluate the performance of the food .........

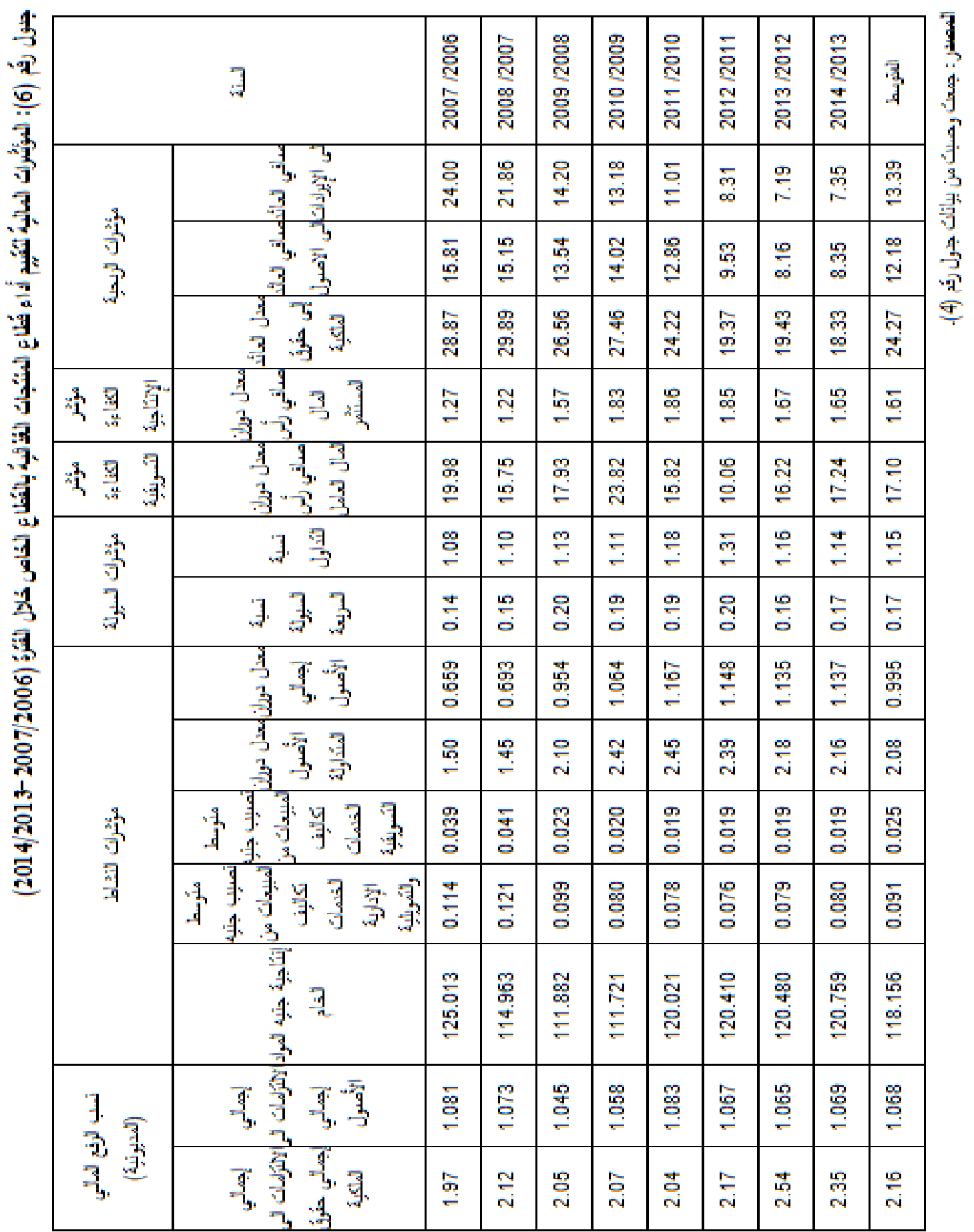


المتاحة وتوليد المبيعات، ويتضح من بيانات الجدولين

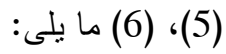

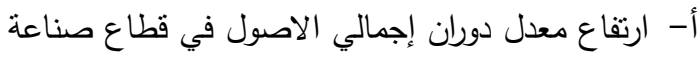
المنتجات الغذائية بكلا القطاعين الخاص والاعمال العام من نحو 0.7\%، 0.6 \% خلا بلإ عام

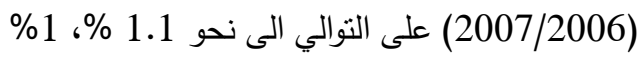
خلال عام (2014/2013) على التوالي بمتوسط بلغ الخ نحو 1\%، 0.7\% خلال متوسط فنرة الدراسة. ب-ارتفاع معدل دوران إجمالي الاصول المتداولة في قطاع صناعة المنتجات الغذائية بكلا القطاعين الخاص والاعمال العام من نحو 1.5 \%، 1.3 \% 1.3 خلال عام (2007/2006) على التوالي الى نحو دالـ

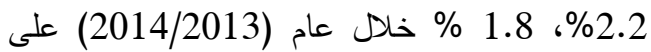
التوالي بمتوسط بلغ نحو 2.1\%، 1.4\% خلال منوسط

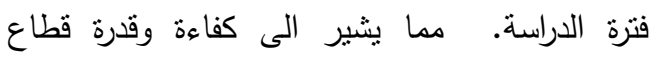
صناعة المنتجات الغذائية بالقطاع الخاص عن مثيله بقطاع الاعمال العام في إدارة أصوله الثابتة والمتداولة وزيادة استغلالها وقدرتها على توليد المبيعات. ج-انخفاض منوسط نصيب جنيه المبيعات من كل من تكاليف الخدمات النسويقية والخدمات الادارية والتمويلية في قطاع صناعة المنتجات الغذائية بالقطاع

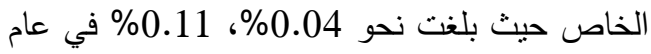

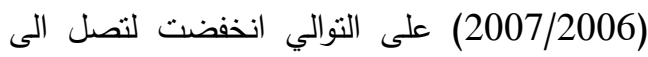
نحو 0.02\%، 0.08\% في عام (2007/2013/2001) بمتوسط بلغ نحو 0.03\%، 0.09\% على التوالي خلال فترة الدراسة. بينما ثبتت تلك النسبتين تقريبا في

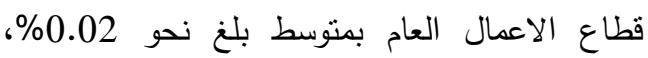

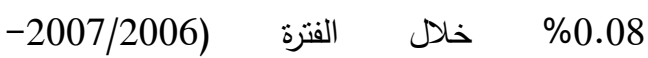
.$(2014 / 2013$

د-انخفاض انتاجية جنيه المواد الخام بقطاع صناعة المنتجات الغذائية بالقطاع الخاص عن مثنيله بقطاع الغاع

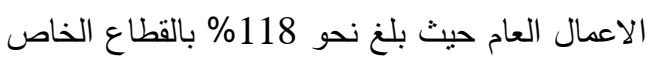
مقابل 137\% لقطاع الاعمال العام كمتوسط للفتزة

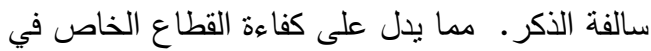

يعنى تزايد الصعوبات التسويقية التي تواجه كلا القطاعين

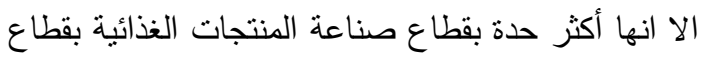
الاعمال العام عن مثيلاتها في القطاع الخاص خلال فترة الدراسة والذي قد يرجع الى الظروف السياسية والاقتصادية التي تمر بها البلاد خلال تلك الفترة.

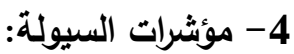

وتتشير الى قدرة القطاع على تحويل الأصول المنداولة

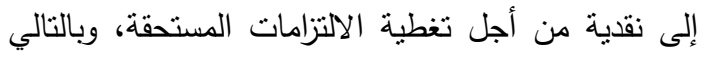

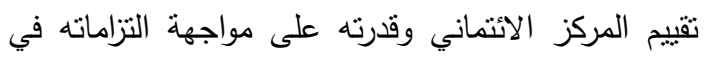

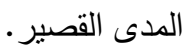

ويتضح من بيانات الجدولين (5)، (6) ما يلي: أ- ثبات نسبى لنسبة التداول في قطاع صناعة المنتجات الغذائية بالقطاع الخاص خلال منوسط فترة الدراسة حيث بلغت نحو 1.2\% كمتوسط للفترة

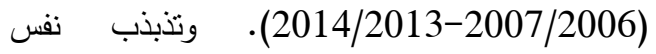
النسبة لقطاع الاعمال العام حيث بلغت نحو 2.04 \% كحد أقصى عام (2012/2011)، و1.3\% كحد الاعمال أدنى في عام (2014/2013) بمتوسط بلغ نحو 1.7\% خلال فترة الدراسة سالفة الذكر. ب-انخفاض نسبة السيولة السريعة لقطاع صناعة

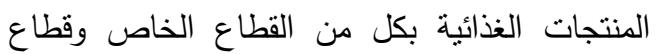
الاعمال العام عن الواحد الصحيح حيث بلغت نحو لإن 0.17 \% 0.20 \% على النوالي كمنوسط لنسبة السيولة السريعة خلال منوسط الفترة (2007/20062014/2013). الامر الذي يدل على انه بالرغم من

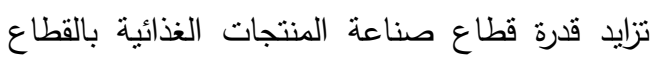
الخاص على مواجهة النزاماته الجارية عن مثنيله بقطاع الاعمال العام الا ان كلا القطاعين غير قادر لعاد على مواجهة التزاماته في الظروف الطارئة والملحة. 5- 5 مؤشرات النشاط: و تقيس مدى نجاح المنشأة في إدارة وتشثغيل مواردها 
من الإنتاج التام على مستوى الأنشطة الصناعية

بمنشآت القطاع الخاص، أعداد متفرقة.

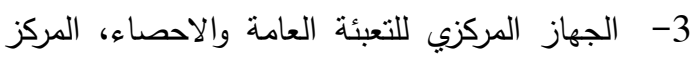

القومي للمعلومات، إدارة الحاسب الآلي، القاهرة.

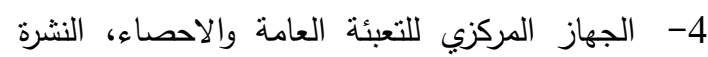

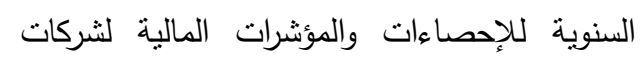

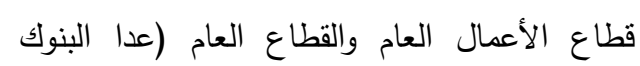
وشركات التأمين)، أعداد متفرقة.

5- الجهاز المركزي للتعبئة العامة والاحصاء، النشرة التهنة

السنوية للإحصاءات والمؤشرات المالية لشركات القطاع الخاص المنظم والاستثماري، أعداد متفرقة.

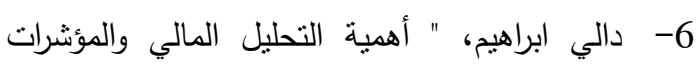
المالية - شرح نظري وعملي كامل"، مكتبة جامعة المالية

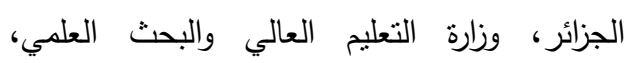
الجمهورية الجزائرية الديمقراطية الثعبية، اكتوبر 2016

7- صالح محمد الفرا، " التحليل المالي"، مدونة للعلوم المالية والادارية، 11 مارس 2013.

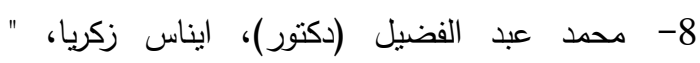
الطاقات العاطلة في الصناعة المصرية "، الادارة

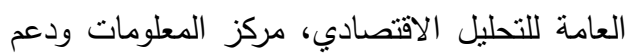
اتخاذ القرار ، مجلس الوزراء، ديسمبر 2005.

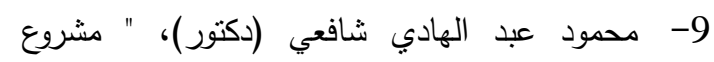
تحسين الكفاءة التسويقية والتصنيعية والتوزيعية للمحاصيل الزراعية "، شعبة الاقتصاد الزراعي ولئي

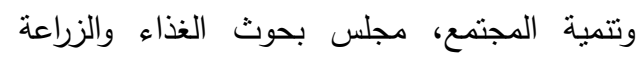
والري، أكاديمية البحث العلمي والتكنولوجيا، يناير الغذاء ولزئي 2007

10- محمد سمير، " قضايا اقتصادية: الصناعات التحويلية في مصر . الواقع والمستقبل " 13 نوفمبر .2014

11- هنادي عبد الراضي (دكتور)، وآخرون، " دراسة

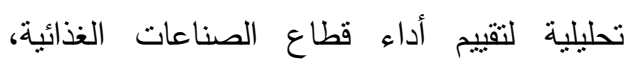
المؤتمر التاسع عثر للجمعية المصرية للاقتصاد

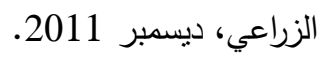

إدارة واستغلال الموارد والإمكانات المتاحة لديه مقارنة بقطاع الاعمال العام. 6- سب الرفع المالي (المديونية):

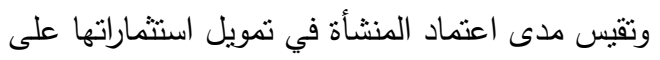
مصادر التمويل الخارجية، ويتضح من بيانات الجدولين (5)، (6) ما يلي: لتوبل أ- ثبات قدرة قطاع صناعة المنتجات الغذائية في كل من القطاع الخاص وقطاع الاعمال العام على سداد

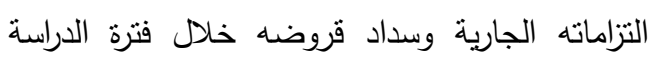
حيث بلغ متوسط إجمالي الخصوم الى الاصول نحو 1\%، 1.1\% لكلا القطاعين على التوالي خلال الفترة .2014/2013-2007/2006) ب-ثبات نسبة إجمالي الالتزامات الى حقوق الملكية في

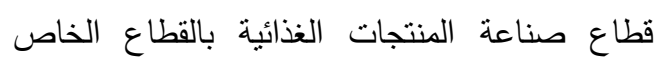
حيث بلغت نحو 2.2\% كمنوسط لفترة الدراسة سالفة الذكر • بينما تذبذبت نللك النسبة لنفس القطاع التابع لقطاع الاعمال العام حيث بلغت نحو 8.4\% كحد أقصى في عام (2012/2011) تتاقصت لتصل الى الى 3.8 كحد أدنى في عام (2014/2013) بمتوسط بلغ نحو 5.2\% خلال فترة الدراسة. الامر الذي عادي

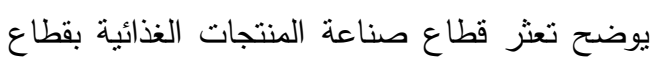

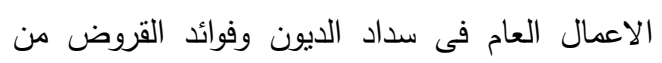
إجمالي حقوق الملكية بدرجة أكبر من مثيله التابع الاعلي للقطاع الخاص.

المراجع 1- الجهاز المركزي للتعبئة العامة والاحصاء، النشرة السنوية للإنتاج الفعلي والطاقة العاطلة والدخزون

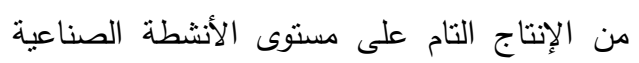
بمنشآت القطاع العام والاعمال العام، أعداد متفرقة.

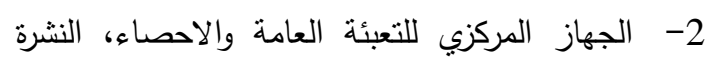
السنوية للإنتاج الفعلي والطاقة العاطلة والمخزون 


\section{الملاحق}

جدول رقم (1): تطور مساهمة الصناعات التحويلية في الناتج المحلي الاجمالي خلال الفترة (2007/2006(القيمة: بالمليون جنيه)

$(2013 / 2012$

\begin{tabular}{|c|c|c|c|}
\hline$\%$ & اجمالي الناتج الدحلى الحقيقي & قيمة الصناعات التحويلية & 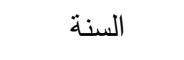 \\
\hline 16.11 & 710388 & 114475 & $2007 / 2006$ \\
\hline 16.25 & 855302 & 139003 & $2008 / 2007$ \\
\hline 16.55 & 994055 & 164523 & $2009 / 2008$ \\
\hline 16.89 & 1150590 & 194290 & $2010 / 2009$ \\
\hline 16.50 & 1309906 & 216184 & $2011 / 2010$ \\
\hline 15.79 & 1508527 & 238283 & $2012 / 2011$ \\
\hline 15.65 & 1677352 & 262505 & $2013 / 2012$ \\
\hline
\end{tabular}

المصدر: النشرة الاقتصادية لمركز تحديث الصناعة المصري، ديسمبر 2013

جدول رقم (2): نسبة المؤثرات المالية لقطاع المنتجات الغذائية إلى إجمالي الصناعات التحويلية بقطاع الاعمال العام

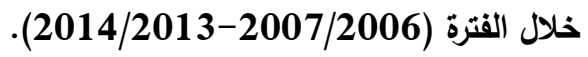

\begin{tabular}{|c|c|c|c|c|c|c|c|c|c|}
\hline الماسل & الجمالي & الخصوم & الأصول & الاناليف & المبيعات & والخسارة & الأجور & (فرد) & السنة \\
\hline 24.4 & 14.3 & 11.8 & 15.8 & 24.3 & 21.5 & 4.8 & 15.6 & 21.3 & 2007/2006 \\
\hline 27.6 & 14.9 & 12.1 & 16.6 & 24.1 & 20.3 & 5.8 & 15.4 & 21.2 & 2008/2007 \\
\hline 19.5 & 12.2 & 10.7 & 14.3 & 22.8 & 23.3 & 3.7 & 17.2 & 21.9 & $2009 / 2008$ \\
\hline 26.0 & 14.6 & 12.1 & 16.6 & 24.7 & 23.2 & 4.3 & 15.9 & 20.6 & 2010/2009 \\
\hline 28.3 & 16.2 & 13.0 & 17.7 & 24.8 & 25.6 & 2.8 & 19.2 & 22.7 & $2011 / 2010$ \\
\hline 29.9 & 16.8 & 13.8 & 18.7 & 30.6 & 31.0 & 0.8 & 20.9 & 27.4 & 2012/2011 \\
\hline 28.1 & 14.8 & 14.2 & 19.7 & 32.0 & 31.6 & 6.8 & 21.1 & 23.1 & 2013/2012 \\
\hline 33.4 & 14.9 & 13.5 & 19.5 & 39.3 & 37.5 & 6.6 & 21.3 & 23.5 & $2014 / 2013$ \\
\hline 26.8 & 14.8 & 12.7 & 17.4 & 28.5 & 27.3 & 4.6 & 19.0 & 22.6 & المتوسط \\
\hline
\end{tabular}


تابع جدول رقم (2): (2) - (2)

\begin{tabular}{|c|c|c|c|c|c|c|c|}
\hline الارصدة النقدية & حقوق الملكية & تكاليف الخدمات & الاداليف الخدمات & الخصدوم & الاصنداولة المن & المال العامل رأس & السنة \\
\hline 6.6 & 5.4 & 22.7 & 10.3 & 7.7 & 14.3 & 45.1 & $2007 / 2006$ \\
\hline 7.3 & 6.5 & 22.6 & 18.9 & 7.4 & 15.4 & 34.7 & $2008 / 2007$ \\
\hline 10.2 & 4.9 & 26.4 & 9.6 & 7.4 & 11.8 & 40.5 & $2009 / 2008$ \\
\hline 11.8 & 5.0 & 24.1 & 22.4 & 8.2 & 16.9 & 42.1 & $2010 / 2009$ \\
\hline 20.6 & 3.8 & 25.8 & 24.5 & 8.0 & 18.7 & 58.7 & $2011 / 2010$ \\
\hline 8.9 & 3.1 & 27.2 & 24.9 & 8.9 & 20.6 & 79.0 & $2012 / 2011$ \\
\hline 18.4 & 6.3 & 27.2 & 22.3 & 13.2 & 22.0 & 22.9 & $2013 / 2012$ \\
\hline 9.6 & 6.1 & 24.7 & 23.2 & 12.2 & 21.7 & 12.0 & $2014 / 2013$ \\
\hline 11.4 & 5.2 & 25.3 & 19.5 & 9.4 & 17.6 & 34.9 & المتوسط \\
\hline
\end{tabular}

المصدر: جمعت وحسبت من بيانات جدولي (3) بالبحث، (3) بالملاحق (") تعبر عن قيم سالبة

جدول رقم (3): تطور أهم معالم قطاع الصناعات التحويلية بقطاع الاعمال العام خلال الفترة (2007/2006(القيمة: بالمليون جنيه) . (2014/2013

\begin{tabular}{|c|c|c|c|c|c|c|c|c|c|}
\hline صافي رأس المال & أسمالي & الخصوم & الأصول & الانتاج & المبيعات & $\begin{array}{c}\text { والربح } \\
\text { والخسارة }\end{array}$ & الأجور & $\begin{array}{l}\text { (فرد) } \\
\text { العمال }\end{array}$ & السنة \\
\hline 31433.9 & 53974.9 & 88632.9 & 66091.8 & 19214.8 & 29382.2 & 23724.1 & 4299.8 & 236.0 & $2007 / 2006$ \\
\hline 29325.8 & 54487.9 & 91248.6 & 66086.4 & 21389.7 & 32426.6 & 26480.3 & 4920.9 & 232.9 & $2008 / 2007$ \\
\hline 43106.3 & 69216.7 & 104166.7 & 78056.2 & 21272.1 & 29533.9 & 25016.4 & 4923.7 & 220.7 & $2009 / 2008$ \\
\hline 32896.5 & 58504.6 & 95416.2 & 69808.1 & 22154.1 & 31770.2 & 28107.9 & 5941.1 & 230.5 & $2010 / 2009$ \\
\hline 33658.4 & 58775.6 & 95914.7 & 70797.4 & 24150.3 & 34369.4 & 28173.0 & 6619.9 & 206.5 & $2011 / 2010$ \\
\hline 35552.4 & 63451.4 & 103767.6 & 75868.6 & 25184.5 & 34305.5 & 29175.9 & 7801.7 & 207.9 & $2012 / 2011$ \\
\hline 33240.6 & 64246.2 & 109451.7 & 78446.0 & 25516.0 & 36324.6 & 33620.0 & 9191.4 & 204.2 & $2013 / 2012$ \\
\hline 29201.4 & 67153.0 & 119355.6 & 81404.0 & 30035.6 & 40912.9 & 40306.7 & 10272.4 & 201.7 & $2014 / 2013$ \\
\hline 33551.9 & 61226.3 & 100994.2 & 273319.8 & 23614.6 & 33628.2 & 29325.5 & 6746.4 & 217.6 & المتوسط \\
\hline
\end{tabular}




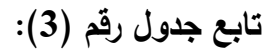

\begin{tabular}{|c|c|c|c|c|c|c|c|}
\hline الارصدة النقدية & حقوق الملكية & تكاليف الخدمات & تكاليف الخدمات & الختداولة & الاصتداولة & 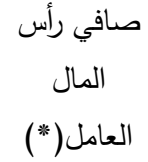 & السنة \\
\hline 7694.1 & 41872.8 & 647.5 & 3573.7 & 37172.5 & 33041.5 & 4131.0 & $2007 / 2006$ \\
\hline 7910.5 & 39399.6 & 679.3 & 3782.0 & 39691.2 & 33425.3 & 6265.9 & 2008/2007 \\
\hline 5609.4 & 46764.5 & 742.2 & 3677.4 & 37617.2 & 43458.1 & 5840.9 & $2009 / 2008$ \\
\hline 5820.0 & 51655.2 & 791.4 & 3229.6 & 37436.0 & 31946.9 & 5489.1 & 2010/2009 \\
\hline 5902.0 & 49214.5 & 872.6 & 960.7 & 37766.5 & 32546.2 & 5220.3 & $2011 / 2010$ \\
\hline 5369.3 & 55185.2 & 922.1 & 3575.8 & 41463.7 & 36591.1 & 4872.6 & $2012 / 2011$ \\
\hline 6537.4 & 59967.2 & 1061.1 & 4538.4 & 46214.3 & 37166.6 & 9047.6 & $2013 / 2012$ \\
\hline 6693.5 & 69639.4 & 1154.8 & 4485.7 & 53559.5 & 38558.4 & 15001.2 & $2014 / 2013$ \\
\hline 6442.0 & 51712.3 & 858.9 & 3727.9 & 41365.1 & 35841.8 & 6983.6 & المتوسط \\
\hline
\end{tabular}

المصدر: جمعت وحسبت من:

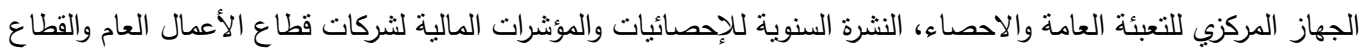
العام (عدا البنوك وشركات الثأمين)، أعداد متفرقة.

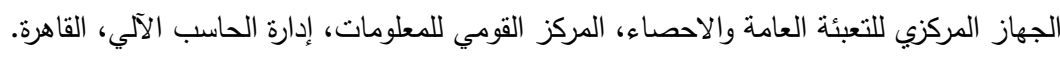
تعبر عن قيم سالبة(")

جدول رقم (4): نسبة المؤشرات المالية لقطاع المنتجات الغذائية إلى إجمالي الصناعات التحويلية بالقطاع الخاص خلال

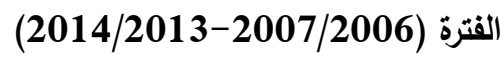

\begin{tabular}{|c|c|c|c|c|c|c|c|c|c|}
\hline صافي رأس & |المال المستي رأسر & الخصوم & الأصول & الانتاج & المبيعات & صالفي & الأجور & عدد العمال & \\
\hline 7.19 & 7.55 & 10.45 & 10.39 & 18.44 & 9.68 & 36.35 & 9.86 & 8.50 & $2007 / 2006$ \\
\hline 8.93 & 9.12 & 10.74 & 10.73 & 15.09 & 13.70 & 39.93 & 11.39 & 8.29 & 2008/2007 \\
\hline 7.98 & 7.91 & 9.21 & 9.34 & 15.48 & 14.36 & 29.56 & 10.08 & 8.01 & 2009/2008 \\
\hline 6.36 & 6.63 & 7.84 & 7.79 & 15.35 & 13.71 & 41.10 & 10.88 & 7.36 & $2010 / 2009$ \\
\hline 6.16 & 6.45 & 7.51 & 7.33 & 14.38 & 13.44 & -35.20 & 10.55 & 7.72 & $2011 / 2010$ \\
\hline 6.07 & 6.24 & 7.16 & 7.04 & 13.76 & 13.58 & -24.94 & 10.17 & 7.96 & $2012 / 2011$ \\
\hline 7.26 & 6.87 & 5.91 & 6.11 & 12.36 & 12.27 & 43.11 & 8.40 & 8.03 & 2013/2012 \\
\hline 6.97 & 6.54 & 5.84 & 5.87 & 11.11 & 11.58 & 56.74 & 9.06 & 7.69 & $2014 / 2013$ \\
\hline 6.97 & 7.00 & 7.65 & 7.66 & 13.90 & 12.73 & 82.87 & 9.83 & 7.92 & المتوسط \\
\hline
\end{tabular}




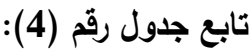

\begin{tabular}{|c|c|c|c|c|c|c|c|}
\hline الارصدة النقدية & حقوق الملكية & تكاليف الخدمات & الادارية والتمويلية & الختدوا & الاصنداولة & صالمال العامل & السنة \\
\hline 6.22 & 9.82 & 14.29 & 5.35 & 13.34 & 11.39 & 4.07 & $2007 / 2006$ \\
\hline 7.30 & 8.50 & 19.61 & 8.95 & 15.38 & 11.01 & 2.89 & $2008 / 2007$ \\
\hline 8.10 & 8.04 & 9.81 & 8.51 & 12.19 & 9.28 & 3.32 & $2009 / 2008$ \\
\hline 7.54 & 7.06 & 8.41 & 6.87 & 9.67 & 7.39 & 2.39 & $2010 / 2009$ \\
\hline 8.27 & 6.32 & 6.09 & 6.65 & 10.60 & 7.00 & 2.45 & $2011 / 2010$ \\
\hline 8.13 & 5.70 & 5.69 & 5.75 & 8.74 & 6.70 & 3.83 & $2012 / 2011$ \\
\hline 7.79 & 4.78 & 6.15 & 5.47 & 6.75 & 5.97 & 3.41 & $2013 / 2012$ \\
\hline 8.57 & 4.78 & 5.62 & 5.09 & 6.86 & 5.78 & 2.76 & $2014 / 2013$ \\
\hline 7.76 & 6.53 & 7.96 & 6.31 & 9.49 & 7.45 & 3.08 & المنتوسط \\
\hline
\end{tabular}

المصدر: جمعت وحسبت من بيانات جدولي (4) بالبحث، (5) بالملاحق

\section{جدول رقم (5) تطور أهم معالم قطاع الصناعات التحويلية بالقطاع الخاص خلال الفترة (2007/2006- (القيمة : بالمليون جنيه) \\ . (2014/2013}

\begin{tabular}{|c|c|c|c|c|c|c|c|c|c|}
\hline المال المستثمر & إجمالي رأس المستثر & الخصوم & الأصول & تكاليف الانتاج| & المبيعات & صافي الربح & الأجور & العمال (فرد) & السنة \\
\hline 50631.36 & 55716.91 & 72577.51 & 67521.92 & 20055.27 & 47739.98 & 3052.00 & 2281.27 & 192.91 & $2007 / 2006$ \\
\hline 42495.66 & 46975.77 & 66817.10 & 62336.99 & 26704.34 & 33813.60 & 2535.79 & 2203.88 & 193.31 & $2008 / 2007$ \\
\hline 54691.41 & 59211.61 & 81327.16 & 76806.96 & 39471.91 & 47599.89 & 3284.89 & 3247.29 & 248.16 & $2009 / 2008$ \\
\hline 66875.85 & 71727.44 & 98822.11 & 93970.52 & 45431.83 & 56822.97 & 2497.56 & 5202.48 & 242.05 & $2010 / 2009$ \\
\hline 73401.49 & 77849.44 & 103767.63 & 98206.68 & 48700.73 & 62537.76 & -2629.89 & 5858.92 & 236.22 & $2011 / 2010$ \\
\hline 75760.31 & 81713.56 & 110256.55 & 105103.31 & 51290.23 & 62558.84 & -2829.72 & 5922.97 & 233.97 & $2012 / 2011$ \\
\hline 70102.46 & 82696.83 & 134956.45 & 122412.17 & 57042.56 & 69249.36 & 1416.56 & 7171.72 & 231.94 & $2013 / 2012$ \\
\hline 74544.69 & 87689.89 & 137854.39 & 128280.24 & 63815.10 & 73896.98 & 1108.05 & 7630.67 & 245.42 & $2014 / 2013$ \\
\hline 63562.90 & 70447.68 & 100797.36 & 94329.85 & 44064.00 & 56777.42 & 1054.40 & 4939.90 & 228.00 & المتوسط \\
\hline
\end{tabular}


تابع جدول رقم (5):

\begin{tabular}{|c|c|c|c|c|c|c|c|}
\hline الارصدة النقدية & حقوق الملكية & تكاليف الخدمات & الادارية والنتمويلية & الخصدوم & الاصتداولة & صافي رأس المال العامل & السنة \\
\hline 6524.09 & 39116.02 & 1255.34 & 9833.87 & 21388.42 & 27076.57 & 5688.15 & $2007 / 2006$ \\
\hline 5841.29 & 39869.22 & 963.93 & 6240.97 & 18845.66 & 29001.39 & 10155.73 & $2008 / 2007$ \\
\hline 7255.10 & 45473.21 & 1593.66 & 7963.31 & 23559.19 & 35055.17 & 11495.98 & $2009 / 2008$ \\
\hline 7171.77 & 52912.87 & 1877.71 & 9020.83 & 29951.11 & 43636.19 & 13685.08 & $2010 / 2009$ \\
\hline 6553.40 & 60416.65 & 2622.25 & 9803.38 & 27399.56 & 49035.98 & 21636.42 & $2011 / 2010$ \\
\hline 6793.93 & 63939.33 & 2863.25 & 11232.63 & 31025.40 & 53086.85 & 22061.45 & $2012 / 2011$ \\
\hline 6762.69 & 65726.07 & 2650.45 & 12221.96 & 49887.69 & 65241.13 & 15353.44 & $2013 / 2012$ \\
\hline 6912.63 & 71693.63 & 2943.22 & 13463.40 & 50424.83 & 68396.95 & 17972.12 & $2014 / 2013$ \\
\hline 6726.86 & 54893.38 & 2096.23 & 9972.54 & 31560.23 & 46316.28 & 14756.05 & المتوسط \\
\hline
\end{tabular}

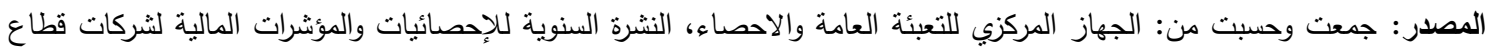

الأعمال العام والقطاع العام (عدا البنوك وشركات التأمين)، أعداد متفرقة. الجهاز المركزي للتعبئة العامة والاحصاء، المركز

القومي للمعلومات، إدارة الحاسب الآلي، القاهرة.

(*) تعبر عن قيم سالبة. 
A comparative analysis study to evaluate the performance of the food .........

\title{
A COMPARATIVE ANALYSIS STUDY TO EVALUATE THE PERFORMANCE OF THE FOOD PRODUCTS INDUSTRY IN EGYPT
}

\author{
Rehab S. Ibrahim \\ Department of Economic Agricultural, Faculty of Agriculture, Ain Shams University
}

\begin{abstract}
The research main objective was the comparative analytical study financial of the sector of food products industry and the reasons for the emergence of idle capacity of both the public and public business sector and the private sector, and adopted the research on descriptive and quantitative analysis by used of averages, percentages and annual rates of growth of the variables were study, and some financial standards and indicators, which measure the profitability of the sector and its ability to meet its financial obligations, and evaluate the extent of production, marketing and administrative efficiency of the sector.

Search on secondary data published and unpublished issued by the CAPMAS, IDSC, Internet, some studies and research related to the search methodology, the search results:

-Increasing real actual production sector of food products industry، the public and public business sector and the private sector the value of a growth rate of about $4.5 \% \cdot 5.5 \%$ respectively during the period (2006 / 2007-2013 / 2014)، as well as the increased value of real energies available to the public and public business sector and the private sector and the growth rate of about $2.7 \%, 5.4 \%$ respectively during the same period.

-That marketing as one of the difficulties associated with market conditions causes are ranked first as one of the causes of idle capacity in the food products industry in both the public and private sectors where both amounted to about $79.5 \%, 49.2 \%$ respectively during the year (2013/2014). The shortage of raw materials as one of the technical reasons for the emergence of idle capacity in the second place by $0.6 \%, 13.4 \%$ for both the public sector and the private sector, respectively, during the year (2013/2014).

-Increasing the proportion of each of the shortage of spare parts and shortage of absent workers in the public sector and public business a amounting to about $0.3 \%, 10.8 \%$ of the total value of idle capacity, respectively, during the year (2013/2014). As well as the increased the proportion of absent workers for up to about $4.8 \%$, while the shortage of spare parts ratio decreased as one of the causes of idle capacity displayed on the private sector to reach about 3.2\% in the year (2013/2014), may be due to changing political and economic conditions in Egypt during the year (2013/2014), which led to a shortage of skilled labor in both the public and private sectors alike.

- Increasing the value of assets، current assets، the value of liabilities، current liabilities، the value of property rights، the capital invested، the total sales, and wages the growth rate of about $2.8 \%, 3.9 \%, 2.9 \%, 5.3 \%, 2.7 \%, 1.8 \%, 5.4 \%, 7.9 \%$ respectively, while decreasing the number of workers of the sector of food products industry's public business sector.

- As well as increasing the value of assets, current assets, the value of liabilities, current liabilities, capital investment, total sales, number of workers, and wages the growth rate of about $0.6 \%, 1.6 \%, 0.5 \%, 0.99 \%, 2.1 \%, 4.2 \%, 0.8 \%, 7.3 \%$ respectively, while the decreased value of the property rights of the food products sector of the industry to the private sector.

- One study of financial indicators turned out to increase the capacity of food products industry in the private sector to make a profit from operating activities compared to that of the public business sector. while The increased capital owned by the owners' confidence in their investments to the sector of food products industry, the public business sector. higher than the private sector.
\end{abstract}


-Increasing the efficiency of the private sector in the use of the capital investment and the projects management of the manufacturing side compared to the performance of the public business sector during the study period.

-Increasing marketing difficulties facing both sectors، but it is more acute the public business sector than in the private sector during the study period، which may be due to the political and economic circumstances in the country during that period.

-Although the increasing ability of the food industry sector to the private sector to meet current obligations higher than the public business sector، but both sectors are unable to facing its obligations in emergency and urgent circumstances.

-The efficiency and capacity of food products industry in the private sector higher than the public business sector in the management of fixed assets and an increase in circulation and use and its ability to generate sales.

-The efficiency of the private sector in the management and exploitation of resources and possibilities available to him compared to the public business sector.

-Stumbled food products industry in the public business sector and debt interest loans from the total equity pay much larger than the private sector alike.

\section{The study recommends:}

1. Encourage private sector investment in the field of food products industry, side by side with the public business sector investments.

2. Increased government spending on research and development as one of the most important for the development of the arts in the production of food products industry and create new products joined the desirability while individuals.

3. Develop products public sector companies to suit the tastes of consumers in addition to modifying the promotional style for their products to suit the conditions of Egyptian society.

Key words: A comparative analysis, efficiency, food products industry, financial indicators, study financial 